\title{
An Assessment of Water/Glass Interactions in Waste Glass Melter Operation
}
A. K. Postma
C. C. Chapman
J. L. Buelt

April 1980

Prepared for the U.S. Department of Energy under Contract DE-AC06-76RLO 1830

Pacific Northwest Laboratory

Operated for the U.S. Department of Energy by Battelle Memorial Institute 


\title{
NOTICH
}

This report was prepared as an account of wark sponsored by the United States GovernmenL. Neiiher the United States nor the Department of Energy. not any of their employees, nor any of their contractors, subcontractors. or their employees, makes any warranty, express or implied. or assumes any legal liability or responsibility for the accuracy, complereness or usefulness of any information, apparatus, product or process disclosed, or represents that its use would not infringe privately owned rights.

The views, opinions and conclusions contained in this report are those of the contractor and do not necessarily represient those of the United States Governmert or the United States Department of Energy.

\author{
PACIFIC NORTHWEST LABORATORY \\ operated by \\ BATTELLE \\ for the \\ UNITED STATES DEPARTMENT OF ENERGY \\ Under Contract DE-AC06-76RLO 1830
}

\author{
Printed in the United States of America \\ Avaibble from \\ National Terhnical information Service \\ United States Depattmant of Commerce \\ 5285 Port Royal Road \\ Springield, Virginia 2351
}

Price: Printed Copys

$\therefore$ Microfiche $\$ 3,00$

$\begin{array}{lc}\text { Pages } & \begin{array}{c}\text { NTIS } \\ \text { Selling Price }\end{array} \\ 001.025 & \$ 4.00 \\ 025-050 & \$ 4.50 \\ 051.075 & \$ 5.25 \\ 076.100 & \$ 6.00 \\ 101-15 & \$ 5.50 \\ 126-150 & \$ 7.25 \\ 157-175 & \$ 9.00 \\ 176.200 & \$ 9.00 \\ 201.225 & \$ 9.25 \\ 226-250 & \$ 9.50 \\ 251.275 & \$ 10.75 \\ 276-300 & \$ 11.00\end{array}$




\section{1}

PNL -2622

UC-70

AN ASSESSMENT OF WATER/GLASS INTERACTIONS

IN WASTE GLASS MELTER OPERATION
A. K. Postma
C. C. Chapman
J. L. Buelt

Apri1 1980

Prepared for

the U.S. Department of Energy

under Contract DE-AC06-76RLO 1830

Pacific Northwest Laboratory

Richland, Washington 99352 
. 


\section{TECHNICAL SUMMARY}

A study was made to assess the possibility of a vapor explosion in a liquid-fed glass melter and during off-standard conditions for other vitrification processes. The glass melter considered is one designed for the vitrification of high-level nuclear wastes and is comprised of a ceramic-lined cavity with electrodes for joule heating and processing equipment required to add feed and withdraw glass. Vapor explosions needed to be considered because experience in other industrial processes has shown that violent interactions can occur if a hot liquid is mixed with a cooler, vaporizable liquid.

Available experimental evidence and theoretical analyses indicate that destructive glass/water interactions are low probability events, if they are possible at all. Under standard conditions, aspects of liquid-fed melter operation which work against explosive interactions include: 1) the aqueous feed is near its boiling point, 2) the feed contains high concentrations of suspended particles, 3) molten glass has high viscosity (greater than 20 poise), and 4) the glass solidifies before film boiling can collapse.

While it was concluded that vapor explosions are not expected in a liquid-fed melter, available information does not allow them to be ruled out altogether. Several precautionary measures which are easily incorporated into melter operation procedures were identified and additional experiments were recommended. 


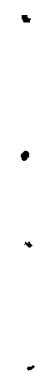




\section{CONTENTS}

TECHNICAL SUMMARY

INTRODUCTION

OBJECTIVES OF THE ASSESSMENT •

SUMMARY AND CONCLUSIONS .

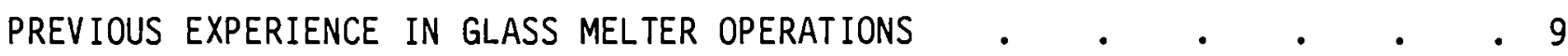

EXPERIENCE IN THE UNITED STATES.

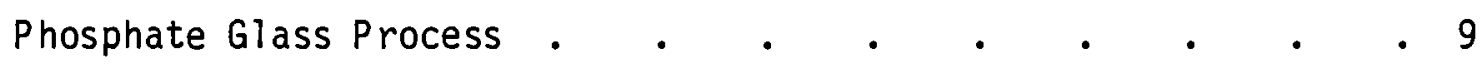

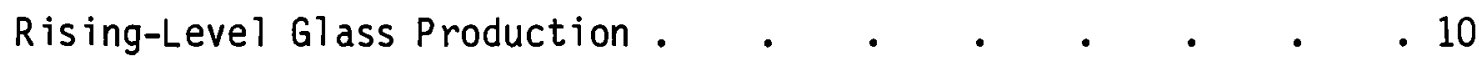

Joule-Heated Ceramic Melter Process _ . . . . . . . 10

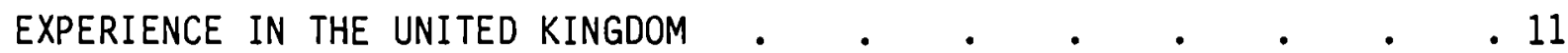

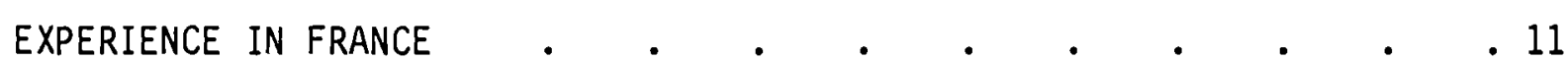

EXPERIENCE IN ITALY •

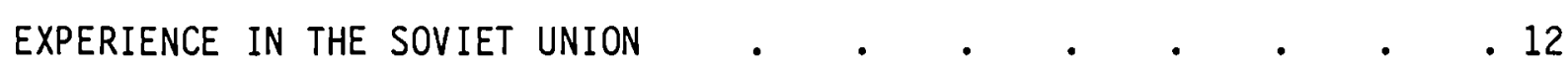

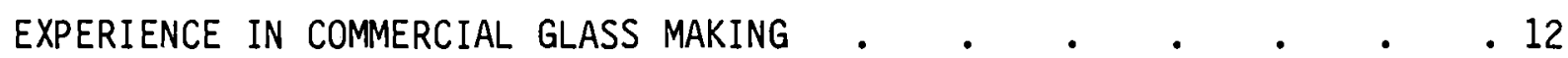

SUMMARY OF GLASS-MAKING EXPERIENCE •

DESCRIPTION OF REPRESENTATIVE STEAM EXPLOSION INCIDENTS $\quad$ • • • • 15

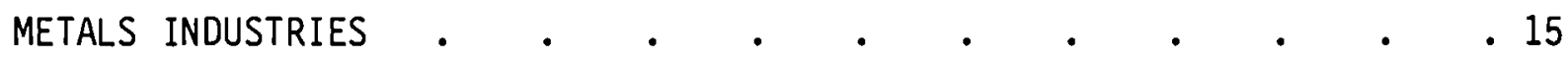

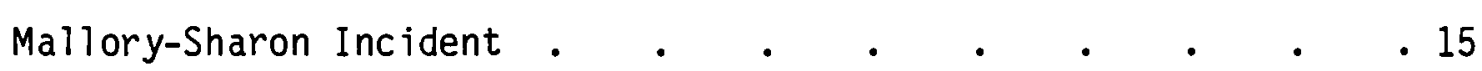

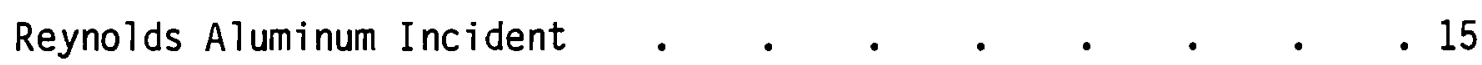

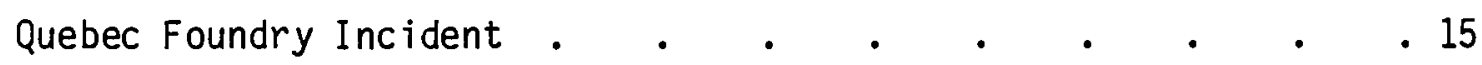

Western Foundries Incident $\quad . \quad$. $\quad . \quad$. $\quad . \quad$. 16

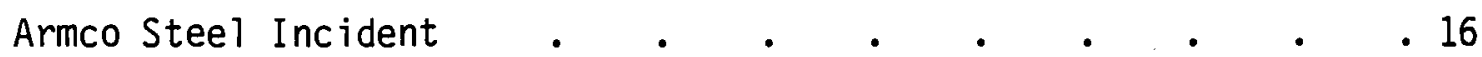

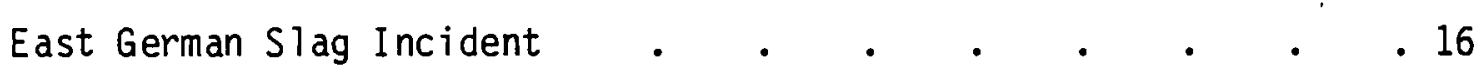

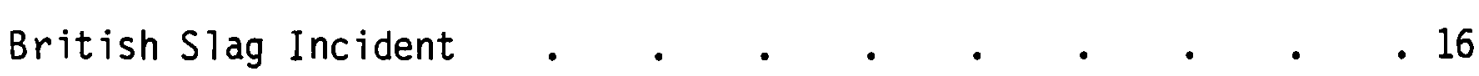


Oregon Metallurgical Corporation Incident $\quad$. $\quad$. $\quad$. 17

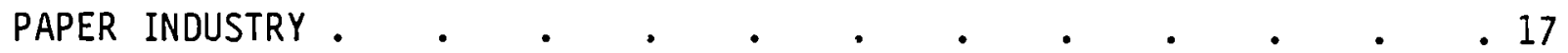

NUCLEAR REACTOR INDUSTRY .

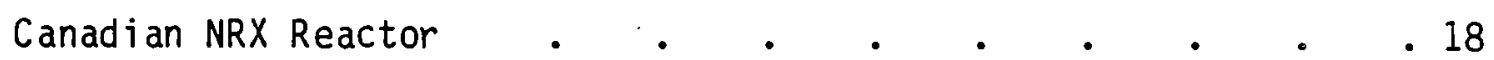

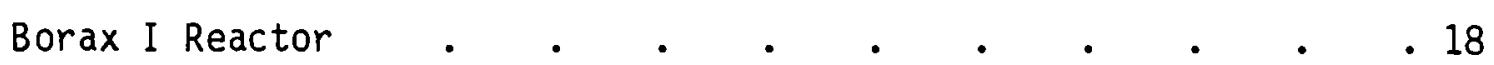

Spert 1-D Reactor . . . . . . . . . . . . . 18

SL-1 Reactor . . . . . . . . . . . . . . 19

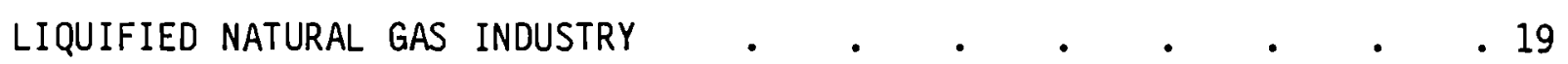

Memphis Light, Gas and Water Division Test . . . . . 20

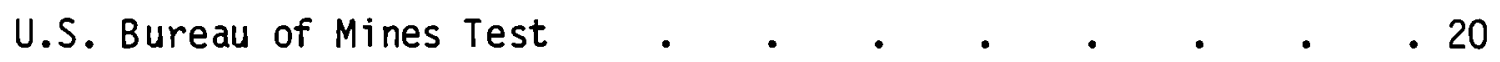

Lava-Water Interactions $\quad$ • $\quad$ • $\quad$ • $\quad$ • 20

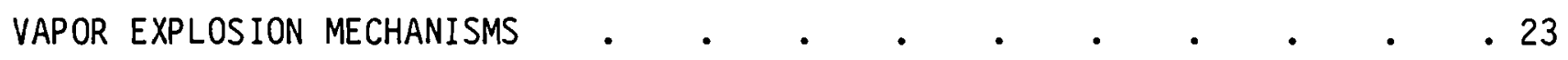

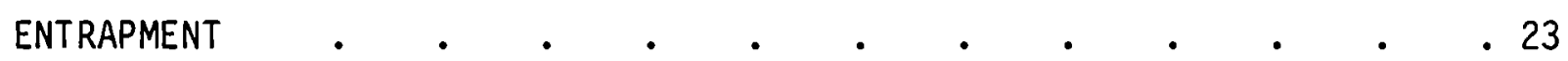

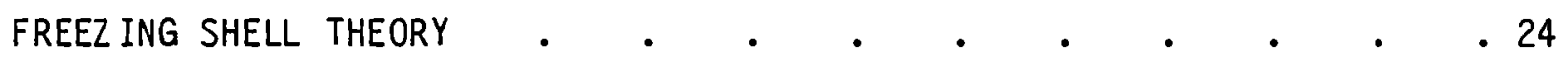

WEBER NUMBER BREAKUP OF DISCONTINUOUS FLUID PHASE • • • • • • 25

SPONTANEOUS NUCLEATION OF SUPERHEATED LIQUID • • • • • • • • 25

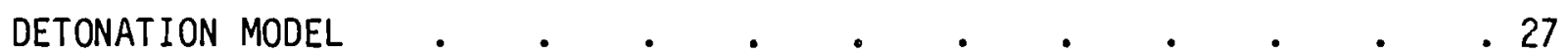

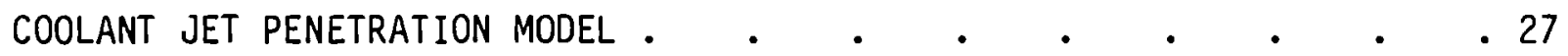

DISCUSSION OF PLAUSIBLE VAPOR EXPLOSION MECHANISMS $\quad$ • $\quad$ • $\quad$ • 28

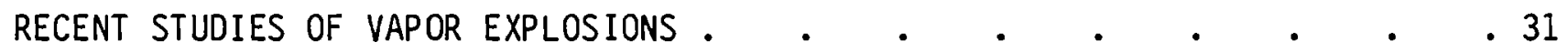

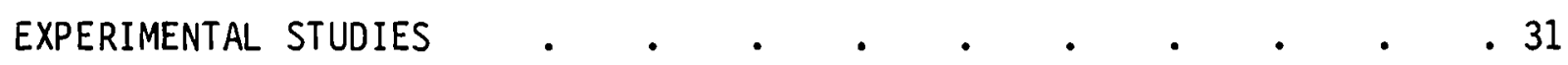

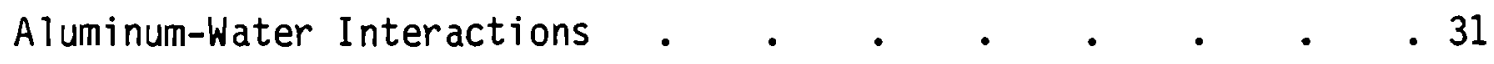

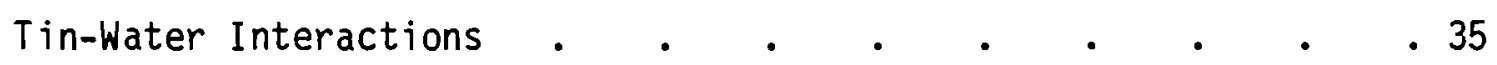

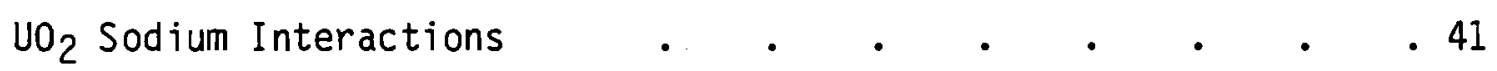

Vapor Explosions with Simulated Fluids . $\quad$ • . $\quad$ • 42 
Water/Glass Interactions Under Natural and Forced

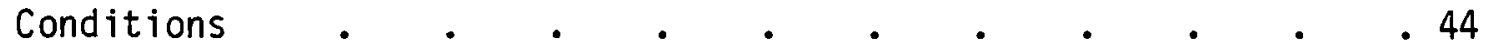

Effect of Dissolved Gases on Vapor Explosions _ . $\quad . \quad$. 46

ASSESSMENT OF THE POTENTIAL OF A VAPOR EXPLOSION IN A LIQUID-FED

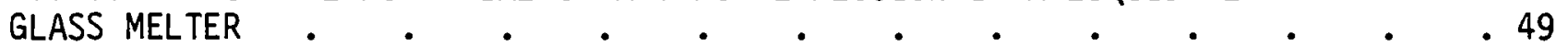

GLASS SOLIDIFICATION PRIOR TO FILM-BOILING COLLAPSE $\quad$ • • • • • 49

SPONTANEOUS NUCLEATION TEMPERATURE AT A LIQUID-LIQUID

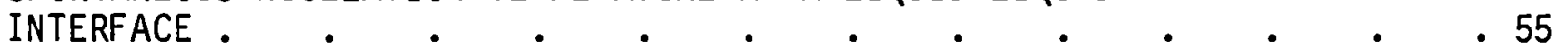

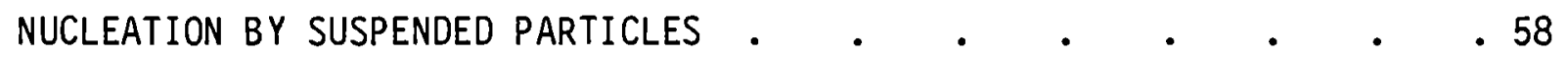

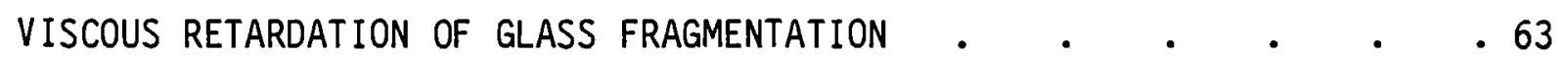

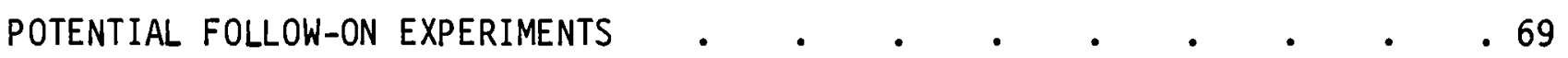

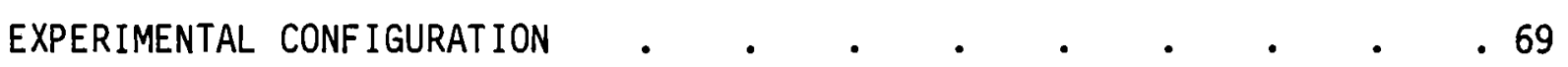

SIZE SCALE $\quad$ • $\quad . \quad$.

VARIABLES TO BE EXPLORED •

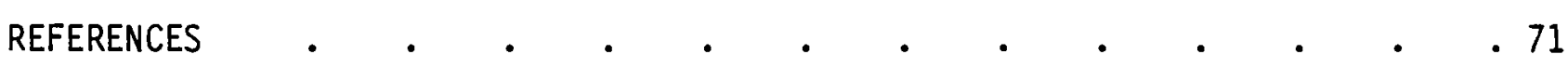




\section{FIGURES}

1 Process Sequence Occurring in a Vapor Explosion . . . . . 29

2 Sketch of Apparatus for Study of Aluminum-Water Interactions . . 32

3 Characteristic Pressure Behavior Found To Describe Molten Metal

Fragmentation in Water . . . . . . . . . . 40

4 Freon-Mineral $0 i 1$ Interactions . . . . . . . . 43

5 Effect of Ambient Pressure on Freon Vapor Explosions . . . . . 43

6 Boiling Heat Transfer Mechanisms . . . . . . . . 50

7 Minimum Glass Surface Temperature Required to Sustain Film-Boiling Based on Correlation of Dhir and Purohit (1977) . • . . . 54

8 Minimum Glass Surface Temperature Required to Sustain Film-Boiling as Predicted in Henry's Correlation (Henry 1974) for 1 atm Pressure . . 56

9 Interface Temperature Established upon Contact of Waste Glass and Aluminum with Water $. . . \quad . \quad . \quad . \quad . \quad .58$

10 Representation of a Nucleated Bubble on a Solid Surface . . . 61

11 Effect of Contact Angle on Spontaneous NucTeation Temperature of

12 Motion at an Interface Between Two Fluids Experiencing

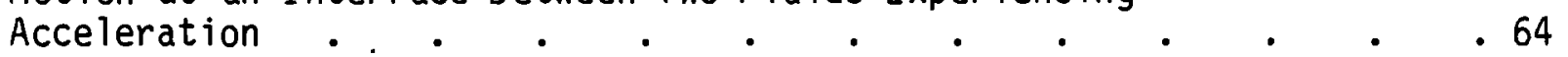

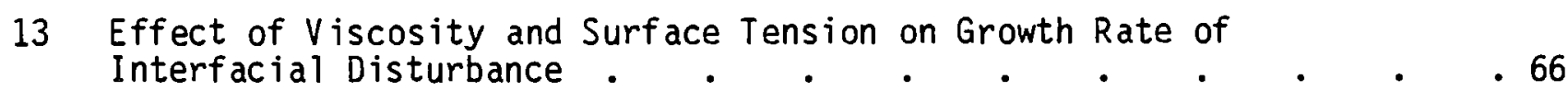

14 Effect of $V$ iscosity on Acceleration Required to Disperse Water/Glass into 1400- $\mu \mathrm{m}$ Globules . . . . . . . . 67 


\section{INTRODUCTION}

This report presents the results of an evaluation of postulated violent interactions between water and molten glass in a waste vitrification process. The vitrification process studied here involves feeding high-level radioactive waste solution and glass-forming chemicals to a joule-heated ceramic melter. Experience with simulated waste shows that this process is promising for converting high-level liquid wastes to glass (Buelt et al. 1979).

On-going safety evaluations of the liquid-fed ceramic melter require knowledge of conditions that foster steam explosions. This is also applicable to other vitrification processes. The possibility of steam explosions must be considered because aqueous solutions come into contact with hot, molten glass during liquid-fed operations, and during some off-standard conditions for other vitrification processes.

Vapor explosions are physical processes where in a liquid is superheated well above its normal boiling point at the prevailing pressure. If the superheating is high enough, spontaneous nucleation can occur, and the resulting flashing of liquid to vapor can be rapid enough to generate shock waves and overpressures which can disperse both the hot and c00l fluids and possibly damage the container. Steam explosions are one category of vapor explosions. Such explosions have sometimes been referred to as "physical" explosions because no chemical reactions need occur.

Considerable experience has accrued world-wide, involving waste glass melters operated with liquid feed. No violent interactions have been reported, showing that steam explosions are unlikely. However, because steam explosions have occurred infrequently in other industrial processes, the absence of violent interactions in previous melter operations may not guarantee that violent interactions will not occur in future glass-making operations.

In this study, we examined the conditions under which vapor explosions can occur and then explored the possibility of such conditions existing in a waste glass melter. This first study of violent interactions between molten 
glass and high-level waste solutions is not expected to answer all the questions that might arise. Rather, it is intended to help determine whether this topic deserves more attention or whether available experience is sufficient to assure that violent interactions are of such low probability that they can be discounted. If additional information is required, then the present study should identify what is needed to $\mathrm{place}$ water/glass interactions in their proper perspective. 


\section{OBJECTIVES OF THE ASSESSMENT}

The primary objective of this study was to determine whether vapor explosions need to be considered in the design and operation of joule-heated melters fed with aqueous high-level radioactive wastes. A secondary objective was to identify the scope of follow-on work, if any, required to evaluate the safety implications of vapor explosions in liquid-fed melters. 



\section{SUMMARY AND CONCLUSIONS}

A study of available information was made to evaluate the possibility of a vapor explosion in a liquid-fed glass melter. In the nuclear waste vitrification process considered herein, aqueous solutions of high-level radioactive wastes are fed to a joule-heated ceramic melter. Water vapor and volatile materials are driven off, and waste oxides react with glass-formers which are also added to the melter to form glass. This vitrification process is mechanically simple compared to alternatives and is therefore a leading candidate for immobilizing defense and power wastes.

Vapor explosions (sometimes called violent glass/water interactions) need to be considered in the liquid-fed melter operation because experience in other industrial processes has shown that violent explosions can occur if a hot liquid is mixed with a cooler, vaporizable liquid. Many necessary conditions must be satisfied before a vapor explosion can occur, and the present study was aimed at determining whether all of the necessary conditions could be met in the liquid-fed melter operation.

Considerable experience has accrued world-wide in the operation of glass melters fed with aqueous solutions. No violent interactions have occurred so $f a r$. This experience and theoretical analyses indicate that destructive water/glass interactions are low probability events, if they are possible at a11. However, the presently available information does not permit one to totally rule out the possibility of a vapor explosion in a liquid-fed glass melter. Additional experimental studies in which molten glass and aqueous waste are purposely mixed are recommended to demonstrate that vapor explosions are not possible within the range of conditions which could be obtained in the melter.

Several precautions have been identified which will minimize the possibility of steam explosions during the time required to complete the follow-on experiments. The four precautionary actions listed on the next page appear to be practical, and will not adversely affect the operation of the existing melters. 
1. The aqueous feed should be preheated prior to entry into the melter. Based on literature data which shows that vapor explosions do not occur if the cool liquid is close to its boiling point, we conservatively recommend that feed not be cooler than $10^{\circ} \mathrm{C}$ below its boiling point.

2. Cooling water circuits used to cool the various parts of the melter should be examined to verify that a rupture in the cooling water conduits would not allow cool water to contact molten glass.

3. Feeding unheated process water to a hot melter should be avoided.

4. Glass product formulations should be designed to avoid the formation of glasses of unusually low viscosity. As shown later in this report, viscous dissipation inhibits vapor explosions. For typical waste glasses which have viscosities greater than 50 poise at $1050^{\circ} \mathrm{C}$, the viscous retardation effect is expected to prevent violent interactions. However, if the glass viscosity were orders of magnitude lower than typical values, the inhibiting effect of viscosity might not alone be sufficient to prevent an interaction. Other conclusions and summary statements supported by the work completed are as follows:

- Vapor explosions occur when an appreciable volume of liquid becomes superheated. If the superheat exceeds the spontaneous nucleation temperature, then sudden flashing of liquid to vapor can generate shock waves and potentially destructive pressure pulses. We have concluded that such interactions are unlikely under standard operating conditions in a liquid-fed glass melter.

- In order to transfer enough heat to superheat a large volume of liquid, the hot liquid must be disintegrated and dispersed into an appreciable volume of the cold liquid. Experimental studies have shown that the collapse of a vapor film can initiate the breakup process. Several vapor collapse and growth cycles may occur in a feedback process leading to pressure pulses large enough to disperse 
the fluids. In the liquid-fed glass melter such disintegration is prevented by stable film boiling and by the high viscosity of molten glass.

- Vapor explosions never occur when the hot material is solid. This is because: 1) solids cannot be finely dispersed by collapsing vapor films, and 2) solids act as nucleators, and it is not possible to appreciably superheat a liquid in the presence of vapor-forming nuclei. In the liquid-fed glass melter one predicts that a typical waste/glass would be solidified before its temperature was low enough to allow a collapse of film boiling. This behavior alone would prevent vapor explosions under standard conditions.

- Small-scale tests with molten glass have shown that vapor explosions did not occur with glass under test conditions which produced explosions when the hot fluid was a molten metal. This supports the statement that the lower thermal diffusivity and higher viscosity of glass work against steam explosions.

- A very large effort is currently underway throughout the world to understand vapor explosions. However, to date, there is not an agreed-upon single model which describes all the sufficient conditions for a vapor explosion. Therefore, it is not possible to predict solely from theory whether a vapor explosion will occur for glass and water under all specified thermal conditions.

- Conditions in the waste glass melter which oppose vapor explosions include: 1) the feed contains suspended solids which would aid nucleation, thereby preventing high degrees of superheat;2) the feed is preheated (experience has shown that steam explosions do not occur when water is hotter than $60^{\circ} \mathrm{C}$ ); and 3 ) glass is highly viscous, thus preventing breakup in the short time required for a vapor explosion.

- Aqueous waste feeds containing powdered frit have a high solidparticle concentration, which decreases the level of superheating that could occur. If these particles acted as nucleating sites, 
superheating-type vapor explosions would be impossible. However, not enough data are available to allow one to totally discount explosive interactions because of the suspended particles.

- Experience shows that dissolved gases, such as $\mathrm{CO}_{2}$, can prevent violent interactions altogether. Hypothetically, the concondensible gases provide a cushion between the two liquids thus disallowing vapor film collapse. This prevents fragmentation of hot liquid and thus no violent interactions occur.

- Experiments involving the intentional mixing of tens of kilograms of molten glass with waste solutions are needed to demonstrate that violent water/glass interactions are not credible under conditions which could be obtained in a liquid-fed melter operation.

Because of the findings of this report, research and development procedures at PNL have been updated to eliminate even the very slight possibility of steam explosions. Beforehand, a few liters of water with no suspended solids have been introduced into the melter before the slurry to cool the noz$z l e$ and prevent caking and plugging of the nozzle. Now, a water-cooled feed nozzle has been installed to eliminate the introduction of unheated process water. Also, procedures have been changed to preheat the feed to $90^{\circ} \mathrm{C}$ which will guarantee no explosions. However, because of process control problems, engineering calculations are being performed to determine whether enough $\mathrm{CO}_{2}$ can be dissolved into the feed during the airlifting step. This report shows that if the $\mathrm{CO}_{2}$ concentrations in water up to $80 \mathrm{ml} \mathrm{kg} \mathrm{kg}^{-1}$ can be attained, which is $10 \%$ of saturated conditions, explosions can be prevented. 


\section{PREVIOUS EXPERIENCE IN GLASS MELTER OPERATIONS}

Previous experience in glass melters operating with aqueous feed was reviewed to find out whether violent water/glass interactions had ever been observed. Our review was based on available information; no doubt other studies exist that are not considered here.

\section{EXPERIENCE IN THE UNITED STATES}

Liquid-fed glass melter operations in the U.S. comprise three major processes: the phosphate-glass process, the rising-level glass process and the joule-heated ceramic melter process. No violent interactions were observed during any of these processes.

Phosphate Glass Process

The phosphate-glass process is a vitrification method developed at Brookhaven National Laboratory in the late 1960's. Phosphoric acid is mixed with high-level waste solutions, and the mixture is heated in a crucible. Water is boiled out and solids are heated to $1100^{\circ} \mathrm{C}$ to $1200^{\circ} \mathrm{C}$ where they form molten glass. Drager et al. (1968) have summarized the bench-scale and pilot-scale development activities of about nine years, including two years of pilot-plant operation.

Pilot-scale melter operations typically involved the feeding of an aqueous concentrate ( $20 \%$ solids) to a platinum crucible $0.2 \mathrm{~m}$ ( $8 \mathrm{in.}$ ) in dia and $0.61 \mathrm{~m}$ (24 in.) long. Glass was formed continuous $1 y$ and was drained from the bottom of the crucible. The feed pipe terminated about $0.15 \mathrm{~m}$ ( 6 in.) above the surface of the melt. While some splattering of feed solution was observed, no violent interactions were ever reported.

Nonradioactive and radioactive phosphate processing was demonstrated on a prototype scale at Pacific Northwest Laboratory (PNL). McElroy et al. (1970, 1971) described solidification operations in which simulated highlevel wastes were converted to glass by the phosphate process. Waste feed containing $10 \%$ to $20 \%$ solids in phosphoric acid slurry was evaporated and converted to molten glass in a platinum melter $0.25 \mathrm{~m}$ ( 10 in.) in dia and 
$0.61 \mathrm{~m}$ (24 in.) long. The feed was concentrated in an evaporation stage and entered the melter at $120^{\circ} \mathrm{C}$ to $135^{\circ} \mathrm{C}$, which was close to the boiling point. Evaporating sludge and feed materials floated on top of phosphate glass, which was maintained at temperatures ranging from $1090^{\circ} \mathrm{C}$ and $1200^{\circ} \mathrm{C}$. During shutdown operations, the feed was diluted with water and acid.

The radioactive runs made at PNL were conducted in two series. In the first series, six runs were completed in a total operating time of about $700 \mathrm{~h}$. The second test series involved five runs, with a total operating time of about $200 \mathrm{~h}$.

Excessive aqueous foaming was observed in the PNL phosphate glass runs until an antifoam agent was added to the aqueous feed. The antifoam material successfully controlled foaming, and no violent interactions were noted during the $900 \mathrm{~h}$ of operation.

Rising-Level Glass Production

One run was made at PNL in which radioactive waste was solidified in the rising-level waste glass process (McElroy et al. 1972). The process involved feeding an aqueous slurry to a stainless steel pot heated to a temperature above the melting point of the glass being formed. In the run completed, glass was formed at $900^{\circ} \mathrm{C}$ to $950^{\circ} \mathrm{C}$. No violent interactions between aqueous feed and hot glass were noted. Water feed was used after about $2.5 \mathrm{~h}$ of operation due to solids bridging in the melting pot. The PNL experience is considered to be an increment to the more extensive experience gained in the United Kingdom with the rising-level glass process.

\section{Joule-Heated Ceramic Melter Process}

Several years of operating experience have been gained in converting liquid waste solutions to a borosilicate glass in a joule-heated ceramic melter (Buelt et al. 1979). Experience has been obtained using two different melters; the larger one had a melting cavity $0.86 \mathrm{~m}$ long, $1.22 \mathrm{~m}$ wide, and $0.48 \mathrm{~m}$ deep. Molten glass temperatures of up to $1150^{\circ} \mathrm{C}$ have been maintained when aqueous feed (including glass-forming chemicals) was added to the top of the melting chamber. To date, 10,000 L of simulated waste have been fed into the large unit. During normal operations the evaporation/calcination/melting 
process proceeded smoothly with no hint of violent interactions between the feed and hot glass. Glass foaming and rapid boiling were noted under some off-standard feeding situations, but no violent water/glass reactions took place.

\section{EXPERIENCE IN THE UNITED KINGDOM}

The British FINGAL process is a rising-level glass production method in which high-level waste slurries are mixed with silica/borax powder and fed to

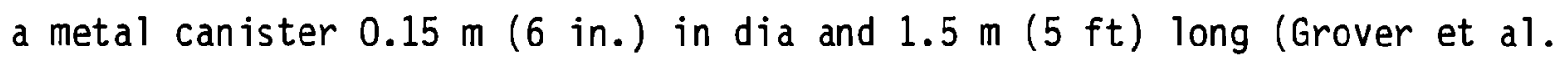
1966). Glass temperatures of $1000^{\circ} \mathrm{C}$ to $1100^{\circ} \mathrm{C}$ are generally maintained.

Davis (1967) reported that the aqueous feed is separated from molten glass by layers of oxides and nitrates. Forty-one test runs were made using simulated nonradioactive solutions; eight runs used radioactive materials. No violent water/glass interactions were noted.

\section{EXPERIENCE IN FRANCE}

French experience in solidifying aqueous waste by means of a rising-leve 1 glass process has been extensive (Bonniaud et al. 1972). The French PIVER process, a rising-level glass method, was studied on a pilot scale over a three-year period at Marcoule. Five runs involving 129 solidification operations produced 10 tons of glass and consumed $19 \mathrm{~m}^{3}$ of high-level waste concentrate. Glass temperatures of $1150^{\circ} \mathrm{C}$ were typically reached. No violent water/glass interactions were reported.

\section{EXPERIENCE IN ITALY}

Small-scale, pilot-plant tests using nonradioactive waste simulants have been performed in Italy in a program designed to perfect a phosphate glass process (Bocola et al. 1972). The stainless steel melter used in the Italian program and $60 \mathrm{~mm}$ in dia and $300 \mathrm{~mm}$ in height. Feed entered at $90^{\circ} \mathrm{C}$, and glass was in the $600^{\circ} \mathrm{C}$ to $800^{\circ} \mathrm{C}$ temperature range during the feeding period. While foaming was sometimes observed to be a problem, no violent glass/solution reactions were noted. 
EXPERIENCE IN THE SOVIET UNION

Konstantinovich et al. (1976) reviewed recent Russian studies on solidification of high-level wastes at a Vienna conference in 1976. This was the only Russian paper studied in the present evaluation.

Russian researchers reported experience in making phosphate glass in a joule-heated ceramic melter that was fed with aqueous waste. The melter was divided into two zones (a making zone and a finishing zone) $2.4 \mathrm{~m}$ and $0.315 \mathrm{~m}$ in length, respectively, and $0.8 \mathrm{~m}$ wide.

The presence of a layer of calcined feed covering the molten glass was necessary to suppress entrainment of feed material in the off-gas circuit. When the layer of feed was broken, pressure in the furnace sharply increased.

Russian experience with this large pilot melter is quite extensive. In experimental studies, $1000 \mathrm{~m}^{3}$ of simulated solution were processed and 250 tons of phosphate glass $\left(100 \mathrm{~m}^{3}\right)$ were obtained. No serious safety problems were uncovered in the development program, and the system was recommended for experimental studies with actual radioactive wastes.

\section{EXPERIENCE IN COMMERCIAL GLASS MAKING}

Several aspects of commercial glass making involve the mixing of molten glass and water and, therefore, provide supportive experience related to waste water/glass interactions.

First, molten glass streams are drained into cool water in the commercial production of pre-melted frit. The rapid quenching of the molten stream causes the glass to solidify, and then fracture into particles which are easily conveyable. To our knowledge, there has never been a destructive vapor explosion caused by this process. Personal contacts made by the authors with several technical people in the frit industry indicate that when very fluid (low viscosity) glasses are quenched, some violence can be generated unless the glass stream is adequately dispersed in the water. The worst situations are more like noisy boiling than the violent explosions which can be caused by the quenching of molten metals in water. 
Second, the water quench pits are commonly provided for the periodic draining of glass melters. The water fractures the drained glass into conveyable particles. No violent destructive explosions have been reported, indicating that water/glass interactions are typically nonviolent.

Third, water streams are often used to cool hot regions on the outside of glass tanks and thereby prevent or terminate glass leaks. Water and glass are intermixed in this process, and violent vapor explosions have not been reported.

\section{SUMMARY OF GLASS-MAKING EXPERIENCE}

This review of glass making experience shows that water/glass interactions are normally benign. Because violent explosions have apparently never occurred, it is evident that steam explosions involving hot glass are lowprobability events, if they are possible at all. The focus of this study should deal with special characteristics of waste glass which could enhance the possibility of a steam explosion in waste vitrification processes. 


\section{DESCRIPTION OF REPRESENTATIVE STEAM EXPLOSION INCIDENTS}

In this section several reported vapor explosion incidents will be described to illustrate the circumstances which have led to past incidents, the diverse nature of interacting fluids, and the magnitude of destructive forces caused by vapor explosions.

\section{METALS INDUSTRIES}

Explosive accidents are infrequent in metals industries, but when they do occur, they result in very damaging physical explosions.

Mallory-Sharon Incident

In this incident in 1954 (Witte et al. 1970), a titanium arc-melting furnace, which was water-cooled, exploded at a plant in Ohio. There were nine injuries, four of which were fatal, and property damage of $\$ 30,000$. The explosion was believed to be the result of water entering the melting crucible. The molten metal inside the melter was exposed to cool water, which subsequently flashed explosively to steam.

Reynolds Aluminum Incident

In this 1958 incident (Witte et al. 1970), an aluminum-water explosion occurred in Illinois involving some forty injuries, six fatalities and approximately $\$ 1,000,000$ in property damage. The explosion "rocked a 25-mile" area. Wet scrap metal was being loaded into a furnace when the explosion was triggered.

Quebec Foundry Incident

This incident (Witte et al. 1970) occurred in a foundry building having a volume of approximately 18 million cubic feet. One hundred pounds of molten steel fell into a shallow trough containing about $78 \mathrm{gal}$. of water. The resulting explosion injured mill personnel (one fatality) and caused $\$ 150,000$ damage to the foundry building including a 20-in. crack in a concrete floor, 6000 broken panes of glass, and structural damage to the walls and ceilings. Another structure, some 75 yd from the foundry, also incurred damage. 
Western Foundries Incident

In this incident, which occurred in 1966 (Witte et al. 1970), a cable broke while 3000 lb of molten steel was being poured from an electric furnace into a tile-lined ladle. Hot steel dropped into a water-filled pit. The result was a violent explosion, injuring three workers and tearing a $600-\mathrm{ft}^{2}$ hole in the roof. The explosion was heard three miles away.

\section{Armco Steel Incident}

The Armco Steel incident occurred in 1967 (Witte et al. 1970). Molten steel fell on "damp" ground, triggering an explosion. A ladle containing 30 tons of molten steel had been elevated $40 \mathrm{ft}$ when it fell. Injuries were sustained by 30 workers; six of those injuries were fatal. Evidently, sufficient moisture was present in the porous ground to trigger small-scale explosions that showered molten steel over a wide area. Although an explosion accompanied the incident, the injuries were primarily attributed to burns received from molten material.

East German Slag Incident

An East German article appearing in 1959 discusses a number of slag-water explosions that have occurred in German open-hearth steel mills (Carbiener et a1. 1974). Two accidents were discussed in which explosions resulted from spraying water on molten slag in open slag pits. One of the explosions resulted in a fatality, a number of other injuries and severe structural damage. The second explosion was less severe. Both explosions were attributed to excess water on the slag, passing down into the cracks to the hot, molten material below. Several other explosions, involving the contacting of water and molten slag, were also described.

\section{British Slag Incident}

In 1964 an explosion occurred in a British steel mill when a ladle, being used to tap a glass furnace, was sprayed with lime-water and returned to service (Carbiener et al. 1974). The next time the ladle was used, it exploded. The ladle was three-fourths full of slag (12 to 14 tons) at the time. Damage to the structure and injuries to personnel were reported. 


\section{Oregon Metal lurgical Corporation Incident}

In 1977 a series of explosions occurred in an Oregon reduction plant when molten magnesium apparently leaked into a pit below a furnace ("Eight Injured in Albany Plant Explosion." The Oregonian, 1977). It was concluded that water had collected in the pit, and a steam explosion was triggered by the contact of molten magnesium with the water. Roofing and siding on the building were stripped from the steel frame, the furnace was damaged and eight people were injured. Several buildings nearby were slightly damaged, and windows rattled in houses more than a mile from the plant.

\section{PAPER INDUSTRY}

Steam explosions occur in the Kraft process in the quench tank used to receive molten salt, which is a chemical ash from the recovery furnace (Sallack 1955; Nelson and Kennedy 1956a, 1956b). While the operation of the "smelt" (molten $\mathrm{Na}_{2} \mathrm{~S}+\mathrm{Na}_{2} \mathrm{CO}_{3}$ ) quench tank may produce explosions more frequently than in other industries, the explosions are not highly destructive and plant operations have been designed to minimize their effect. The following description by Nelson and Kennedy (1956b) typifies the more violent explosions which can occur when smelt is quenched in water:

"On occasion the sound became a deep, powerful rumble or an earthquakelike detonation which occurred far below the surface of quench liquor in the tank. These muffled explosions sometimes caused the unit or even the entire building to tremble. Deep explosions in rare instances have been powerful enough to blow a tank top and metal grating upward more than six feet. Tanks have been split along welded side seams and displaced from foundations by particularly bad underwater explosions."

In comparison to molten metals, molten salts evidently lead to much less violent steam explosions, demonstrating that the physical properties of the hot fluid have an important effect on the explosion process. 
NUCLEAR REACTOR INDUSTRY

Explosive fuel/coolant interactions have occurred when power excursions in small nuclear reactors caused molten metal fuel elements to mix with coolant water. Experience (Carbiener et al. 1974) in the reactor industry is summarized below.

Canadian NRX Reactor

In 1952 at Chalk River, Ontario, during a low-power experiment, a nuclear excursion was experienced (Carbiener et al. 1974). Although the duration of the incident was less than $62 \mathrm{~s}$, the damage was sufficient to result in contamination of the facility. The reaction between uranium and steam (or water) was the principle cause of damage.

\section{Borax I Reactor}

In 1954 at the National Reactor Testing Station in Idaho, the Borax I reactor was deliberately subjected to a potentially damaging power excursion in reactor safety studies (Carbiener et a1. 1974). A power excursion lasting approximately $30 \mathrm{~ms}$ produced a peak power of 19,000 MW with a total energy release of 135 MWs. The power excursion melted most of the fuel elements. The reaction tank (1/2-in. steel) was ruptured by the pressure (probably in excess of 10,000 psi) which resulted from the reaction between the molten metal and the water. The sound of the explosion at the control station (1/2 $\mathrm{mi}$ away) was comparable to the detonation of 1 to $21 \mathrm{~b}$ of $40 \%$ dynamite.

\section{Spert 1-D Reactor}

During the final phase of the destructive test program with the SPERT 1-D core, damaging pressure generation was observed (Carbiener et a1. 1974). Pressure transducers recorded the generation of a pressure pulse larger than 3000 psi which caused the destruction of the core. The pressure pulse occurred some $15 \mathrm{~ms}$ after initiation of the power excursion. The power excursion rapidly overheated the fuel plates; the increased temperature melted the metal and the cladding of the fuel plates. After the transient, much of the fuel that had been molten was found dispersed in the coolant. 


\section{$\underline{\text { SL-1 Reactor }}$}

In January 1961 a nuclear excursion occurred in the SL-1 reactor in Idaho (Carbiener et al. 1974). The total energy released in the excursion was approximately $130 \mathrm{MWs}$ and was produced in the outer fuel elements in the core. This portion of the energy was slowly transferred to the water coolant over a two-second period, and no melting (uranium-aluminum alloy fue 1 ) of the outer fuel occurred. About 50 to $60 \mathrm{MWs}$ of the total energy was released in less than 30 ms by 12 heavily damaged inner fuel elements to the water coolant. This prompt energy release resulted in rapid steam formation in the core which accelerated the water above the core and produced a water hammer that hit the pressure vessel lid. The vessel, weighing about 30,000 1b with its internals, sheared its connecting piping and was lifted approximately $9 \mathrm{ft}$ into the air by the momentum transferred from the water hammer. Calculations of the mechanical deformation of the vesse 1 indicate that about $12 \%$ of the prompt energy release or $4.7 \%$ of the total nuclear release was converted into mechanical energy.

The possibility of vapor explosions in nuclear accidents has prompted an extensive study of vapor explosions related to nuclear safety. Most of the current work on vapor explosions is devoted to understanding possible fuel/ coolant interactions which could affect the safety of reactor cores. At present, most attention is being focused on sodium coolant and $\mathrm{UO}_{2}$ fue 1 because this fuel coolant pair is presently proposed for use in liquid-metal fast-breeder reactors (LMFBR).

\section{LIQUIFIED NATURAL GAS INDUSTRY}

Vapor explosions have been observed when low-boiling hydrocarbons are spilled as subcooled liquids onto water (Nakanishi and Reid 1971; Katz and Sliepcevich 1971; Drake and Reid 1977). In this case, the hydrocarbon floats on top of the water and is the substance which vapor explodes. The density regime for the hot and cool liquids is similar to that which would be obtained in a glass melter where water floats on top of hot glass. While no major industrial accidents have been attributed to vapor explosions of liquified hydrocarbons, several sizeable explosions have occurred in tests (Nakanishi and Reid 1971). 
Memphis Light, Gas and Water Division Test

This firm built an earthen reservoir, $5 \mathrm{ft}$ in dia by $1 \mathrm{ft}$ deep, into which liquified natural gas (LNG) was periodically poured and ignited to give operators experience in extinguishing fires. On one occasion (Nakanishi and Reid 1971), there was approximately 1 in. of water in the bottom of the reservoir when some $50 \mathrm{gal}$. of LNG was poured into it. The LNG was successively ignited and extinguished approximately ten times after which time there was about 1 in. of LNG remaining on top of the ice. The LNG residue was left to bo il off when a loud explosion apparently occurred without ignition. Dirt and ice chunks were thrown 30 to $50 \mathrm{ft}$ from the hole. The violent reaction occurred about 5 min after the last extinguishment.

U.S. Bureau of Mines Test

Under contract to the U.S. Coast Guard, the U.S. Bureau of Mines conducted a number of tests to study the heat transfer between LNG and water (Nakan ishi and Reid 1971). To accomplish this, LNG was poured onto the sur$f$ ace of water contained in a small aquarium tank. In conducting tests with salt water, the first LNG experiment was conducted without incident. In the second test, there was an explosion which destroyed the apparatus. This event occurred in the fifty-sixth test of the series. There had been no indication of a violent reaction in any of the preceeding tests.

These experiments show that vapor explosions between water and lowboiling hydrocarbons are possible, but have much lower probabilities of occurrence and lower violence measurements than metal-water explosions.

\section{Lava-Water Interactions}

Molten lava can apparently react explosively with sea water (Colgate and Sigurgeirsson 1973). Colgate and Sigurgeirsson discuss (p. 20) instability mechanisms which could lead to breakup of lava in contact with water. Their calculations support the postulate that steam explosions are responsible for volcanic explosions. The Krakatoa volcanic explosion, one example cited by these authors, apparently distributed millions of tons of micron-sized particles into the atmosphere. This explosion was extremely powerful, and indicates that some of the largest and most powerful explosions ever to occur on earth may have been vapor explosions. 
By way of recounting, all examples of vapor explosions have involved the intermixing of a hot liquid with a cooler vaporizable liquid. Somehow, the cooler fluid is heated well above its boiling point before vapor formation begins. When vapor formation is triggered, vapor forms at a rate too rapid to be relieved without shock waves, and an explosion takes place. The fact that vapor explosions occur so seldomly indicates that the necessary conditions are quite restrictive. 



\section{VAPOR EXPLOSION MECHANISMS}

In order to assess the possibility of a vapor explosion occurring in a glass melter, it is necessary that the physical processes which lead to rapid vapor formation be understood. In this report section, the various explosion mechanisms will be reviewed, and those which seem most plausible in the light of experimental data will be identified.

\section{ENTRAPMENT}

In the entrapment theory (Witte et al. 1970; Witte and Cox 1978; Flory, Paoli and Mesler 1969; Long 1957; Hess and Brondyke 1969), it is postulated that the cooler vaporizable fluid somehow becomes entrapped by the hot fluid which solidifies and thus forms a pressure barrier to inhibit the escape of the cool fluid and its vapor. The cool fluid then becomes heated by conduction, and finally the contained pressure bursts the solid barrier, resulting in liquid-liquid dispersion and a subsequent vapor explosion.

Evidence in favor of the entrapment theory is ambivalent at best, and this theory has been largely discredited.

The entrapment theory apparently evolved from Long's experiments (1957) in which molten aluminum was dropped into water. Long observed photographically that explosions did not occur until the aluminum had reached the bottom of the water container and had spread out. The hypothesis of the entrapment theory is that the spread aluminum solidified and thus trapped some water beneath it; it was this trapped water that became heated to high pressure and ruptured the metal seal explosively. Entrapment by solids is not a necessary condition for a vapor explosion as evidenced by work where the hot fluid is always above its melting point. Examples of explosive interactions where both liquids remained fluids are mercury and water (Bradley and Witte 1972), and freon and mineral oil (Henry et al. 1974). The entrapment theory is further discredited by the observation that solid boundaries are not required to cause explosive interactions between a hot and cold liquid. Bradley and Witte (1972, p. 25), for example, was able to obtain explosive interactions between a low-melting lead-tin alloy and water when the hot alloy was injected into 
the water as a horizontal jet. The explosive interactions occurred in the bulk of the water, well away from the tank walls.

Based on the experimental evidence available, it is certain that entrapment of liquid by a solid is not a necessary condition for a vapor explosion. Therefore, glass/water interactions in a liquid-fed melter cannot be dealt with by merely avoiding the mixing of molten glass and water where entrapment of water by solid glass could occur.

\section{FREEZING SHELL THEORY}

Two different mechanisms have been postulated to result from the freezing of an outer layer of hot globule. One is a variation of the entrapment theory. It is postulated that when the outer surface of the globule freezes, cracks and fissures develop (Witte et al. 1970, Nelson and Kennedy 1956b, Brauer, Green and Mesler 1968) into which liquid penetrates, vapor then forms in these cracks with explosive violence, causing segments of the shell "to spall off much like shrapnel." This picture of vapor explosions can be dismissed for the same reason as the entrapment mechanism: namely, vapor explosions can occur when no solids are present.

A second freezing shell mechanism involves the creation of a jet of molten metal by the shrinking of the solid shell (Colgate and Sigurgeirsson 1973; Zyszkowski 1976). The molten metal jet is envisioned to penetrate a vapor film blanket which separates the main bulk of hot and cool materials. Direct liquid-liquid contact leads to superheating of the cool fluid, resulting in a vapor explosion. While it is conceivable that this jet formation may play a role in some vapor explosions, it is clearly not a condition necessary for vapor explosions, because explosions can occur without the formation of solid shells.

The elimination of the freezing shell mechanism as a necessary condition means that the shrinkage of solid glass and surface crack formation probably have little relation to the possibility of vapor explosion in a liquid-fed ceramic melter. 
WEBER NUMBER BREAKUP OF DISCONTINUOUS FLUID PHASE

In this proposed mechanism, one liquid stream entering the second is dispersed into small particles by aerodynamic forces (Witte et al. 1970). Due to the enhanced surface area, heat transfer becomes so fast that vapor is explosively generated.

This proposed mechanism has little experimental basis and, indeed, does not agree with visual and photographic evidence of liquid globules prior to a vapor explosion. The observations (Nelson and Kennedy 1956a; Long 1957; Zyszkowski 1976; Bjorkquist 1975) show that the metal globules typically remain largely intact prior to explosive fragmentation. Also, the fact that fragmentation of a molten salt (Nelson and Kennedy 1956a) or aluminum stream (Long 1957) reduces vapor explosion violence shows that fragmentation of the hot liquid leads to results which are opposite those predicted by this proposed mechanism.

When applied to the liquid-fed melter, the failure of the Weber Number fragmentation theory shows that one could not eliminate vapor explosions by designing the liquid feed system to avoid water jets from entering molten glass.

SPONTANEOUS NUCLEATION OF SUPERHEATED LIQUID

In this postulated mechanism (Nakanishi and Reid 1971; Katz and Sliepcevich 1971; Fauske 1973, 1974), the cool liquid is heated by direct liquid-liquid contact with the hot liquid. Because of the absence of a vapor phase and nucleation sites, the cool liquid becomes highly superheated. Finally, spontaneous nucleation forms vapor bubbles in the body of the superheated liquid and, once vapor bubbles appear, flashing occurs very rapidly, leading to vapor explosions.

The spontaneous nucleation of superheated liquid mechanisms is supported by a substantial body of theoretical and experimental information. A few examples of supportive data follow.

First, the phenomenon of superheated liquids is well proven in experiments (Reid 1976; Wismer 1922; Skripov 1974). A simple way to demonstrate 
liquid superheat is to inject water drops into oil that is hotter than the boiling point of water at the prevailing pressure. Briggs (1950) quotes Clerk Maxwell's 1871 edition of Theory of Heat: "In an experiment due to Defour, the water... is dropped into a mixture of 1 inseed $0 i 1$ and oil of cloves, which has nearly the same density as itself...Drops of liquid may sometimes be observed swimming in the mixture at a temperature of $180^{\circ} \mathrm{C}\left(356^{\circ} \mathrm{F}\right) . "$ Liquidliquid heating may be done without the presence of a vapor phase, and since no vapor phase is present, the transition from liquid to vapor which would normally occur at the boiling point does not occur unless a vapor phase is formed spontaneously in the liquid.

Second, nucleation theory has been applied to spontaneous nucleation of superheated liquids, and it has been shown that the nucleation rate is predicted to increase by several orders of magnitude per degree Centigrade (Skripov 1974; Blander and Katz 1975). Thus, until a critical temperature level is reached, the vapor nucleation rate is negligibly small. Above the critical temperature, the nucleation rate is so large that explosive boiling is expected. Thus, if a liquid is heated by another liquid in the absence of nucleation sites to the "spontaneous nucleation temperature" an explosive flashing to vapor is expected.

Third, experiments in which liquids are heated by immersion in a hot liquid show that explosive boiling occurs if the interface temperature exceeds the spontaneous nucleation temperature. This has been observed in single-drop temperature-gradient columns (Reid 1976; Blander and Katz 1975) and in largescale mixing experiments (Henry et a1. 1974).

Major questions remain which apply the spontaneous nucleation model to the water/glass interaction. These questions center on how much water can be superheated to which degree prior to flashing. As will be discussed later in this report, phenomena which severely constrain superheating are: 1) vapor films associated with film boiling, 2) solidification of the glass before liquid-liquid contact and 3) nucleation by solids in the liquid. 
DETONATION MODEL

A detonation model of vapor explosions was formulated in 1975 by Board, Hall and Hall (1975). This model is based on detonation phenomena known to occur in chemical explosions. In this model, it is first assumed that a coarse intermixing of the two fluids takes place by an unspecified process. Then, due to some initiating mechanism, a shock wave is initiated. The shock wave sets up an acceleration of the two fluids which causes fine fragmentation of the hot material. Due to the extremely fine fragmentation hypothesized, heat transfer occurs so fast that the shock is self-propagating.

The plausibility of the detonation model has been questioned by Williams (1976) and by Bankoff, Jo and Ganguli (1976) on the grounds that disintegration of the hot liquid would not occur rapidly enough or to the fineness required to support a detonation. However, other experiments (Patel and Theof anous 1978) tend to support the plausibility of the detonation model. At present it is not possible to state with certainty whether a self-sustaining detonation, water/glass interaction is possible.

Because high degrees of liquid superheat are not required in the detonation model, the solids content of high-level waste feed would not prevent a vapor explosion in a glass melter if a detonation-type interaction were possible. However, the time required for breakup of molten glass globules increases as viscosity increases (Bellman and Pennington 1954), so detonation would be impossible for glass viscosities higher than some critical value.

COOLANT JET PENETRATION MODEL

In this model advanced by Buchanan (1974), a fluid mechanical model is pictured which allows cool liquid to be dispersed into the hot fuel. Rapid heat transfer between the cool and hot fluid then causes very rapid vaporization of the cool fluid, with subsequent disintegration of the hot fluid. A cyclic process is thus envisioned which causes disintegration and intermixing of two fluids. 
The liquid jet which penetrates the hot material is attributed to the collapse of a vapor bubble. It has been shown (Plesset and Chapman 1971) that a so-called "plesset Jet" is formed by the collapse of a spherical cavity in a liquid.

If this model is correct, then vapor explosions in a glass melter could be prevented by always feeding the waste at the saturation temperature. A rapid collapse of the vapor bubble is impossible unless the cool liquid is sub-cooled. High viscosity would also work against break-up by the Plesset Jet.

\section{DISCUSSION OF PLAUSIBLE VAPOR EXPLOSION MECHANISMS}

Of the mechanisms which have been proposed, several which involve fragmentation of the hot fluid remain as credible possibilities. The process sequence (Witte and Cox 1978; Board, Farmer and Poole 1974) which describes vapor explosions is pictured in Figure 1 . As indicated in the figure, an initiating mechanism leads to mechanical energy or motion between the two liquids. The relative motion produces fragmentation of at least one of the fluids, and this greatly enhances the heat transfer area. Rapid heat transfer causes the vapor pressure formation of the cool fluid, and expansion of this vapor causes the observed explosion. A feedback process may be involved to enhance the interphase heat transfer rate.

Several details of the explosion process are not well known at present. Chief among these is the initiating mechanism which leads to fragmentation.

All of the initiating mechanisms indicated in Figure 1 have experimental and theoretical support, as will be described later in this report. The fact that the initiating mechanism is not known to be unique means that an accepted theory to predict the necessary and sufficient conditions for a vapor explosion is not presently available. 


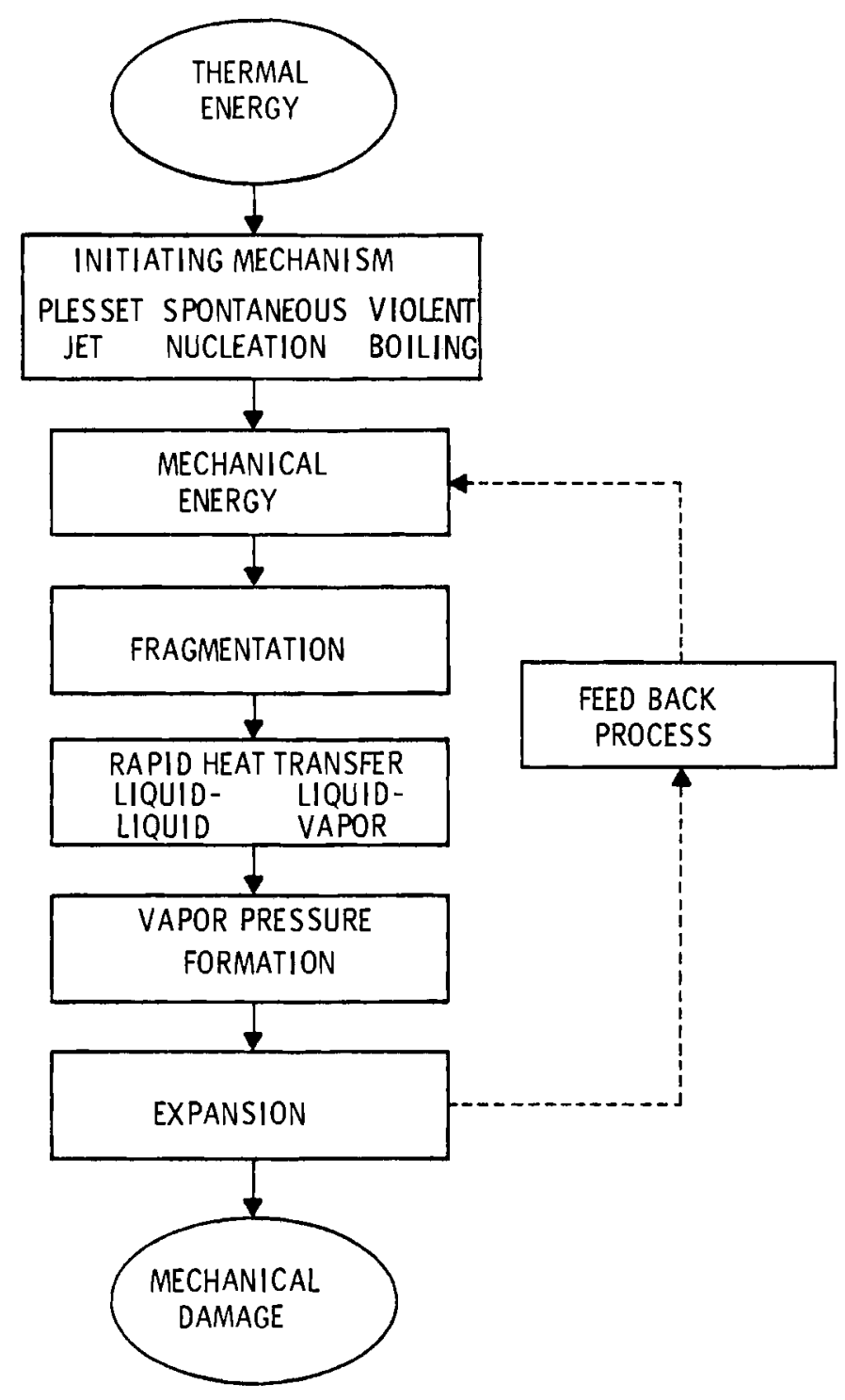

FIGURE 1. Process Sequence Occurring in a Vapor Explosion 
.

.

. 


\section{RECENT STUDIES OF VAPOR EXPLOSIONS}

In this section, selected studies of vapor explosions will be reviewed to show the circumstances under which violent interactions have occurred, and to show how the conceptual models described herein explain the experimental findings.

\section{EXPER IMENTAL STUDIES}

\section{Aluminum-Water Interactions}

Many large-scale experiments have been carried out by researchers at the Aluminum Company of America (Long 1957; Hess and Brondyke 1969) in which molten aluminum was dropped into open pans of water. The apparatus used is described in Figure 2.

In a typical test, 50 1b of molten aluminum was suddenly discharged through a 3 1/4-in.-dia hole into a steel container of water. Long (1957) carried out a total of 880 tests of this type and studied the effect of metal stream quality, water depth and temperature, water additives and types of coating in the steel container. Hess and Brondyke (1969) carried out another 108 of these tests, and focussed on coatings that could be used to prevent explosions.

Explosions of varying intensity were produced in many of the tests. The relatively nonviolent interactions scattered water and molten metal but did not rupture the container. The most violent explosions broke the container and hurled pieces several hundred feet. Phenomenological observations of greatest significance are given in the following subsections.

\section{Water Temperature}

In 34 tests conducted under metal stream conditions which favored explosions, explosions occurred in 18 tests when the water temperature was $0^{\circ} \mathrm{C}$ to $50^{\circ} \mathrm{C}$. No explosion occurred in water which was $60^{\circ} \mathrm{C}$ to $100^{\circ} \mathrm{C}$. These observations are consistent with an initiating mechanism based on a collapsing vapor film, because highly subcooled water favors the transition from film to transitional boiling. 


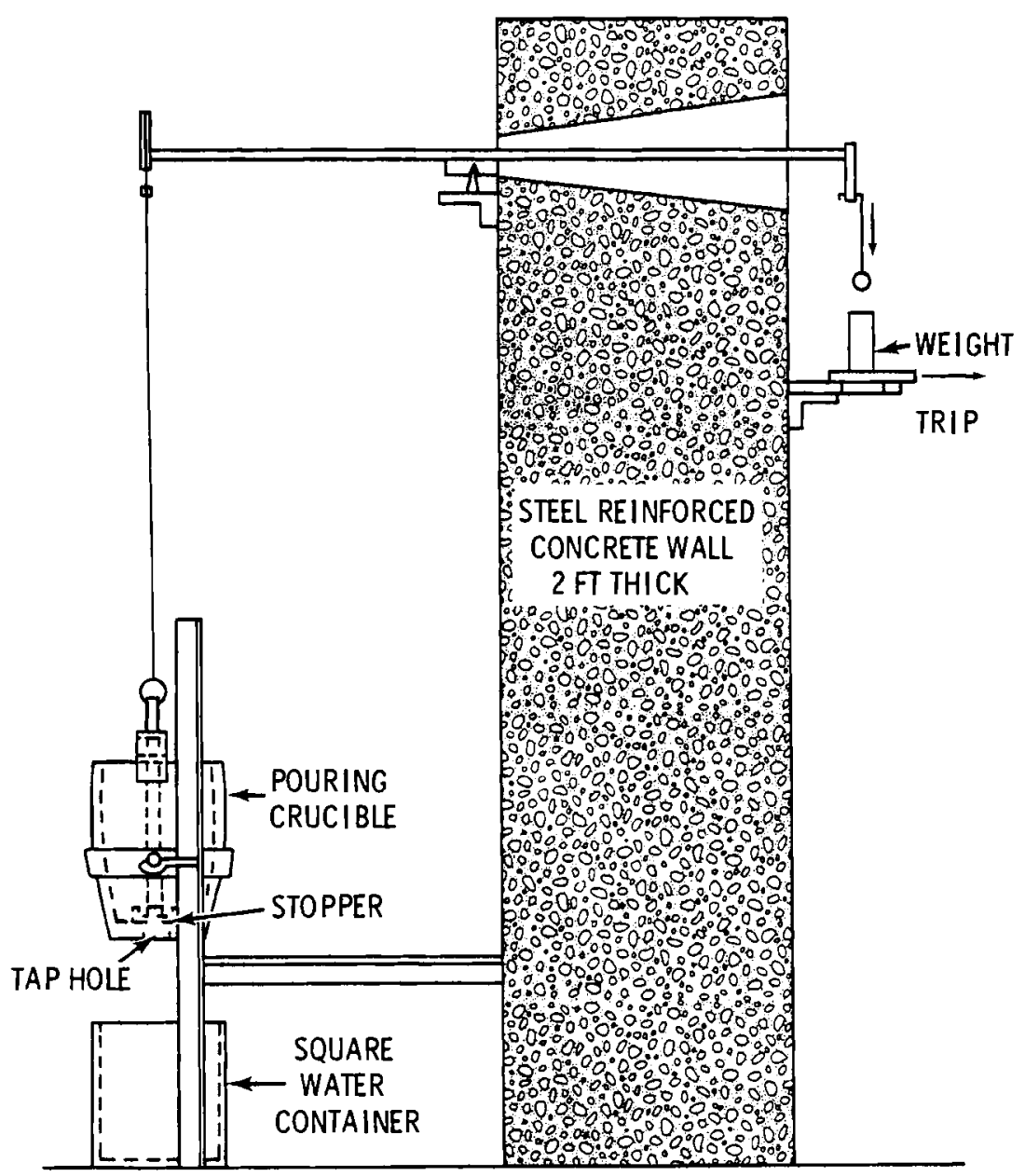

FIGURE 2. Sketch of Apparatus for Study of AluminumWater Interactions (Long 1957; Hess and Brondyke 1969)

\section{Additives in Water}

It was found that the addition of soluble organic materials (0.5\%) prevented explosions, and that salts enhanced explosions. These observations are consistent with initiating mechanisms based on the breakdown of $f i 1 m$ boiling. Organic material touching the metal would decompose into gases, providing nucleation sites for boiling, and the gases would also cushion any vapor-film collapse. On the other hand, salts would aid wetting of metals by water and wetting favors vapor film collapse and superheating of the liquid. 


\section{Water Depth and Metal Temperature}

The metal temperature and the water depth required to produce explosions were found to be inversely related, with a pool depth of less than 6 in. metal at $670^{\circ} \mathrm{C}$ (just slightly above the melting point of $660^{\circ} \mathrm{C}$ ) producing an explosion. However, as water depth increased to 30 in., no explosions occurred even with metal at $900^{\circ} \mathrm{C}$. These observations suggest that the metal must be at a minimum temperature by the time it spreads on the bottom of the pool. Deeper water requires a high initial temperature of the metal.

\section{Coatings on the Water Tank}

It was found that explosions could be prevented by covering the water tank with organic coatings, but that explosions were enhanced when oxide or hydroxide coatings were used. These findings were consistent with expectations based on the model pictured in Figure 1. The organic materials apparently decomposed when contacted by hot metal, providing gases which would cushion vapor film collapse and provide nucleation sites to avoid superheating. As expected, the coatings lost their effectiveness after several exposures to hot metal, when volatiles had been largely driven off. The enhancement due to inorganic oxides and hydroxides lies in enhanced wetting which would favor vapor-film breakdown and, more importantly for oxides, exothermic chemical reactions (thermite-type) which would add to the heat energy available.

\section{Metal Stream Quality}

The ability to produce an explosion was found to depend on the size of the molten metal stream which entered the water. No explosions occurred when the metal was discharged through 3/4-in., 1-1/2-in. and 2-1/2-in.-dia holes. Increasing the hole size to $2-3 / 4$ in., $3-1 / 4$ in. and 4 in., respectively, resulted in explosions.

In addition to the drain hole size, it was found that the distance the metal fell prior to contacting the bottom of the water container was important. For example, explosions occurred when the distance the metal fell was less than $4 \mathrm{ft}$, but no explosions occurred in 19 tests using a 10-ft drop. 
Long (1957) tentatively concluded that fall height had an effect on stream breakup and tested the hypothesis by placing a steel grid with $1-i n .^{2}$ openings over the water container. This grid prevented explosions in 13 tests under conditions that without the grid produced explosions.

Several interpretations of the metal stream characteristics are possible. First, there may be a size scale effect in vapor explosions, as would be expected in the detonation model of Board, Hall and Hall (1975). It may be that when the metal is broken into smaller globules, that a small explosion by the first metal globules provides a steam phase, preventing superheating of water by metal entering later. A third possibility is that smaller metal globules are not susceptible to fragmentation, although other experiments discount this possibility.

\section{Physical Properties of Molten Metal}

In order to evaluate the effect of the hot stream properties, Long (1957) carried out 19 tests using molten magnesium and an unspecified number of tests with molten salt made from equimolar amounts of sodium chloride and potassium chloride.

Results obtained for molten magnesium were indistinguishable from those for molten aluminum. However, for the molten salt several differences were observed: the salt explosion was less intense than metal-induced explosions; the salt explosions were not prevented by the 20-in. water depth, by the grease coating or by the soluble oil.

The differences between metal and molten salt explosions can be attributed to differences in the thermal properties of these fluids. The much lower thermal conductivity of the salt would yield lower interface temperatures with water. This lower interface temperature would reduce heat transfer, explaining the lower explosive yields and the greater water depths which permit explosions. Also, the organic coatings would decompose much less rapidly and the noncondensable gas, which inhibits vapor film collapse and superheating, would not be generated in time to prevent the explosion. 
Tin-Water Interactions

Following the very extensive large-scale tests on aluminum-water interactions by Long (1957) and by Hess and Brondyke (1969), a number of researchers have carried out small-scale tests using many different molten metals. Molten tin apparently has been studied more extensively than any metal except aluminum, so selected results of available studies will be noted.

\section{Fragmentation Study of Flory, Paoli and Mesler (1969)}

These authors reported tests in which molten metals ( $\mathrm{Pb}, \mathrm{Sn}, \mathrm{Bi}, \mathrm{Al}, \mathrm{Cu}$, $\mathrm{Hg}$ and low melting alloys) were dropped into water baths. High-speed photography was used to record the fragmentation process. Also, the solidified fragments were studied to obtain a measure of the degree of fragmentation. Several interesting observations included the following:

- larger drops fragmented more violently than smaller ones;

- lowering the surface tension of aluminum by adding bismuth enhanced the degree of fragmentation;

- the addition of powdered carboxymethylcellulose to the water had a marked effect on reducing or preventing fragmentation (carboxymethylcellulose would increase the viscosity of water and also decompose into gases when heated by molten metal; both of these factors would reduce fragmentation, so the observed effect is expected);

- fragmentation decreased when the water-batch temperature was above $25^{\circ} \mathrm{C}$, and no fragmentation occurred with water-batch temperatures of $90^{\circ} \mathrm{C}$ to $100^{\circ} \mathrm{C}$.

\section{Explosive Interactions of Molten Metals Injected into Water}

Bradley and Witte (1972) injected molten metals into water using a horizontally positioned nozzle. The metal entered the water as a jet, and interactions which occurred were far from any wall or solid interface. Metals tested included tin, mercury and alloys of $\mathrm{Pb} / \mathrm{Sn}$ and $\mathrm{Bi} / \mathrm{Pb} / \mathrm{Sn} / \mathrm{Cd}$. These four metals had different melting points, allowing melting point effects to be demonstrated. 
In a typical experiment, the temperature of the molten metal was increased in steps, and water/metal interactions were studied by monitoring the noise produced, the extent of fragmentation in cooled metal and the flowrate of metal through the injection nozzle. Explosive interactions were characterized by audible "blasts," by extensive fragmentation of cooled metal and by flow reversal in the nozzle caused by pressure pulses in the water at the nozzle exit.

Explosive interactions were obtained for all four metals when a threshold metal temperature was exceeded. For mercury, tin, and the lead/tin alloy, expolosive interactions were apparent for metal temperatures above about $290^{\circ} \mathrm{C}$. For the $\mathrm{Bi} / \mathrm{Pb} / \mathrm{Sn} / \mathrm{Cd}$ alloy, explosive interactions occurred at temperatures about $200^{\circ} \mathrm{C}$.

These experiments are particularly informative because they demonstrate conclusively the following:

- solidification of the metal is not necessary to cause an explosive interaction, as shown by the mercury results.

- the presence of a solid interface is not required to obtain an explosive interaction.

- large globules of hot materials are not required to obtain explosive interactions.

These experiments are consistent with the explosive processes listed in Figure 1 and allow us to remove the shrinking she 11 mechanism and the solid entrapment mechanism from those processes necessary in vapor explosions.

\section{Molten Tin Dropped into Water}

While we will not attempt to review all studies involving molten tin dropped into water, three studies by different investigators will be described because they add insight into the mechanisms that cause vapor explosions.

Arakeri et a1. (1975) dropped 25-g globules of molten tin into water and studied the interaction photographically, by fast-response pressure measurements, and also examined the solidified fragments of tin after the drop. 
Both water temperature and tin temperature varied as parameters. Consistent vapor explosions were observed only at the two highest tin temperatures of $787^{\circ} \mathrm{C}$ and $676^{\circ} \mathrm{C}$ and when the water batch temperature was uniform and below $52^{\circ} \mathrm{C}$ (lowest bath temperature was $8^{\circ} \mathrm{C}$ ). Only occasional vapor explosions were observed at initial tin temperatures of $537^{\circ} \mathrm{C}$, and no vapor explosions were detected at initial tin temperatures of $426^{\circ} \mathrm{C}$ and $343^{\circ}$. The intensity of the explosions that occurred appeared to be unrelated to the water temperature provided it was below $52^{\circ} \mathrm{C}$.

The degree of fragmentation was directly related to the magnitude of the peak pressure pulse. When the tin solidified as nonporous, sizeable fragments, no explosions occurred. The highest peak pressure pulses were associated with solidified tin particles described as "fine porous fragmentation with final product split up." These observations are consistent with the expectation that the amount of vapor produced would increase with the heat transfer rate. The heat transfer rate would, of course, increase as the hot material became more finely subdivided.

Photographic observations of the falling tin globule showed that, typically, three or four local interactions occurred before the whole globule was involved in interaction. The interactions, evident as distortions in the metal surface, were apparently due to the collapse of vapor films which separated water and hot metal. When total fragmentation occurred, a vapor explosion occurred. The estimated time from the beginning of the first interaction to the maximum growth of the last interaction was $10 \mathrm{~ms}$.

The metal and water temperature limits when explosions occurred fit reasonably with Fauske's (1973) spontaneous nucleation model. It postulated that vapor explosions can occur without delay only if the instantaneous interface temperature of the cool fluid is higher than the spontaneous nucleation temperature.

Arakeri's (Arakeri et a1. 1975) results are consistent with other metalwater interaction experiments and with the vapor explosion process diagram pictured in Figure 1. 
Board, Farmer and Poole (1974), at the Berkeley Nuclear Laboratories in England, dropped a few grams of molten tin into water and measured pressure pulses as well as obtaining high-speed photographs of the tin-water interaction. The experimental arrangement was quite similar to that employed by Arakeri et al. (1975).

In the first type of experiment, a few grams of tin were dropped into an open tank of water. It was found that explosions occurred only if both the tin was above $400^{\circ} \mathrm{C}$ and the water was below $60^{\circ} \mathrm{C}$. The high-speed photographs revealed that multiple interactions of increasing violence occurred prior to whole drop involvement. Vapor films (or bubbles) grew and then collapsed. The growth and collapse of the preliminary interaction could be observed from the pressure trace. It was this observed growth and collapse cycle, with subsequent cycles being more violent, that leads these researchers to postulate a feedback mechanism as pictured in Figure 1.

A second type of experiment carried out by Board, Farmer and Poole (1974) involved the dropping of molten tin into water at $\sim 40^{\circ} \mathrm{C}$ maintained at a low pressure ( 0.1 bar). Under these conditions the water was subcooled less than the critical value, and no explosions occurred unless the pressure on the system was suddenly increased. The increased pressure apparently caused the vapor film to collapse, triggering an explosion.

In a third type of experiment, Board, Farmer and Poole (1974) applied a mechanical disturbance to a tin drop supported on a crucible under water at $80^{\circ} \mathrm{C}$. Although no interactions occurred at this temperature under quiescent conditions, a light hammer blow was found to trigger multiple thermal interactions. No such interactions could be triggered at a water temperature of $95^{\circ} \mathrm{C}$.

The experiments of Board, Farmer and Poole (1974) lend support to the importance of vapor film collapse, at high velocity, as a prime triggering process in vapor explosions. This postulate is consistent with the other experimental work discussed in this report. The collapse phenomenon apparently explains the fact that vapor explosions apparently cannot be triggered if the cool liquid is at or near its boiling point. This is important in the 
ceramic melter as it shows that vapor explosions would be impossible if the aqueous feed were close to its boiling point, a condition nearly always obtained in melter operation.

G.M. Bjorkquist (1975) at MIT, dropped tin and bismuth drops (6 to $10 \mathrm{~g}$ each) into water and studied the interaction photographically with a fastresponding pressure transducer, and evaluated the fragmentation of the cooled metal. The apparatus was similar to those employed by Arakeri et al. (1975) and by Board, Farmer and Poole (1974).

An interesting aspect of Bjorkquist's (1975) experiment was the pressure curve found to characterize metal drop fragmentation. The pressure curve is pictured schematically in Figure 3.

1. The initial high frequency period corresponds to film boiling. Film boiling persists until the metal cools to the Leidenfrost point, which is where transitional boiling begins.

2. When the film boiling stops, liquid-liquid contact occurs and the cool fluid undergoes superheating. The quiescent period of Figure 3 corresponds to the initial superheating period.

3. Once the cool fluid is superheated to the spontaneous nucleation temperature, there is localized flashing to vapor. If the cool liquid is cool enough, the vapor is condensed, allowing bubble collapse. This cycle is repeated a number of times in a "prebang high frequency cycle."

4. The bubble collapse and liquid flashing cycles escalate in severity and cause a "big bang" when the metal drop is broken into small fragments which can rapidly transfer heat to the liquid. Photographs verified that catastrophic fragmentation occurred at the time of the "big bang."

This four-step picture of a thermal explosion appears to be consistent with the experiments we are aware of and the processes described in Figure 1. Other interesting phenomena observed by Bjorkquist (1975) follow.

The peak pressure generated by the interaction was found to depend on the initial drop temperature. Essentially no over-pressure was generated for 


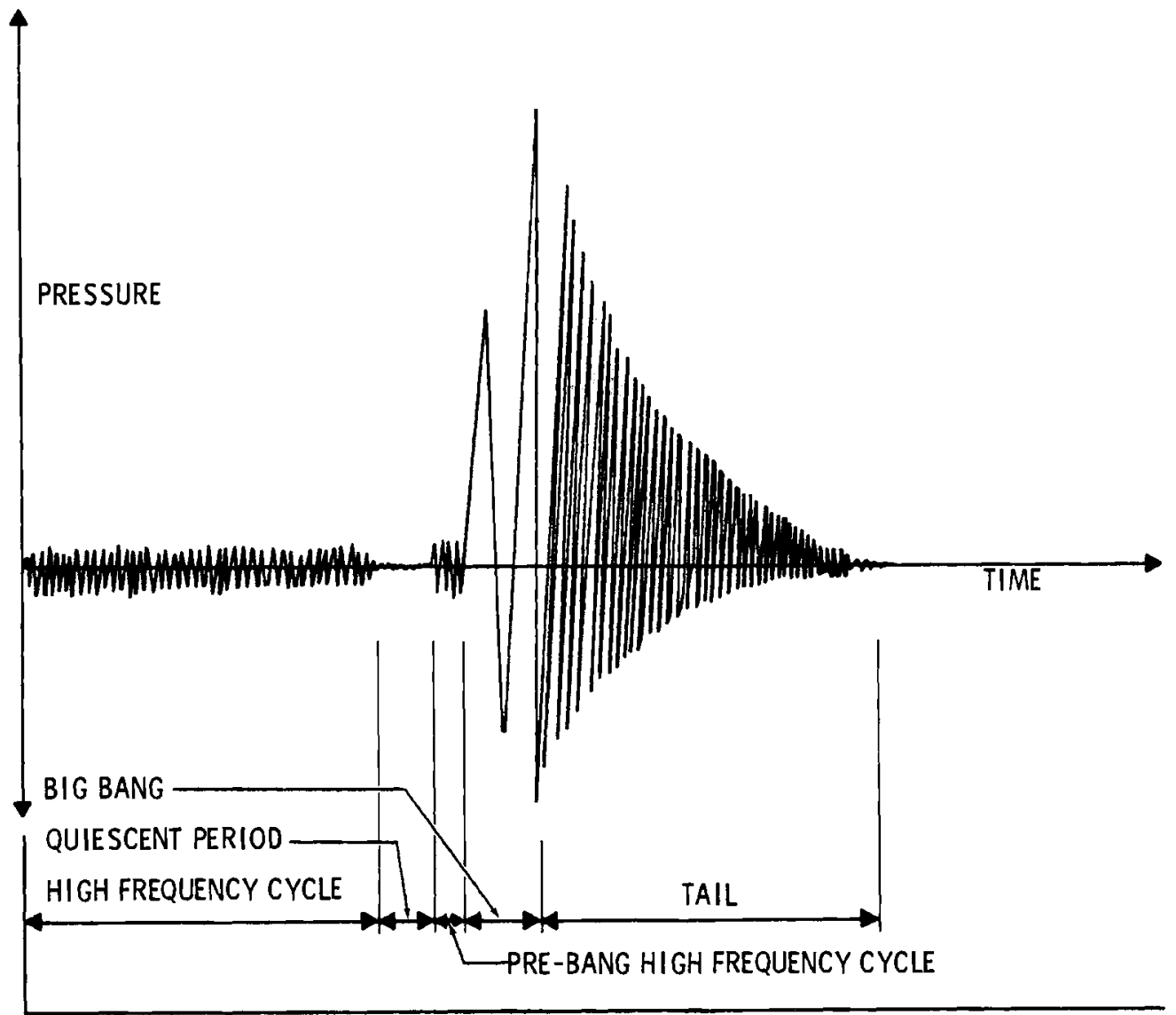

FIGURE 3. Characteristic Pressure Behavior Found To Describe Molten Metal Fragmentation in Water (Bjorkquist 1975)

tin temperatures of $400^{\circ} \mathrm{C}$ and below. Between $500^{\circ} \mathrm{C}$ and $700^{\circ} \mathrm{C}$ the peak pressure increased to $250 \mathrm{psi}$. As the tin temperature increased beyond $700^{\circ} \mathrm{C}$, the peak pressure dropped markedly. At $1000^{\circ} \mathrm{C}$, no significant pressure pulses were generated even though the metal drop was fragmented. The fact that hot-metal drops fragmented without producing a violent interaction demonstrates that a coherent disintegration process, under high-heat transfer conditions, is required to generate an explosion. If an incoherent disintegration occurs, then only noisy boiling ensues.

Measurements and calculations carried out by Bjorkquist (1975) showed that the tin cooled by $f i l \mathrm{~m}$.boiling until a temperature of about $600^{\circ} \mathrm{C}$ was reached before fragmentation occurred. Thus, film boiling must cease before a vapor explosion can be triggered. This may be important for water/glass interations because for many glasses the viscosity at a temperature where film boiling broke down would be too high to allow fragmentation by vapor-film collapse. 
$\underline{U O}_{2}$-Sodium Interactions

A great deal of experimental work has been carried out with molten $\mathrm{UO}_{2}$ and sodium because of the importance of these materials in the LMFBR program. Much of this work has been done at Argonne National Laboratory. A recent review by Board and Caldarola (1977) described many of the studies carried out. Only two representative works will be discussed here.

Small-scale vapor explosions were observed by Armstrong (1972) when sodium at $400^{\circ} \mathrm{C}$ was injected into molten $\mathrm{UO}_{2}$ at $3000^{\circ} \mathrm{C}$. These results are in contrast to experiments where in molten $\mathrm{UO}_{2}$ was injected into liquid sodium under similar thermal conditions. These test results led Fauske (1973) to propose a heat transfer model wherein a drop of sodium became entrapped in molten $\mathrm{UO}_{2}$ and, due to a lack of nucleation sites, became superheated. At the spontaneous nucleation temperature, the sodium flashed to vapor, causing the observed explosion.

These experiments of Armstrong are mirror images of most other water/ metal tests which involved hot drops surrounded by a cool fluid. When the cool drop is surrounded by the hot fluid, there is no requirement for fragmentation. Rather, all that is needed is to wait for the hottest part of the cool fluid to exceed the spontaneous nucleation temperature. This mode of producing a vapor explosion is similar to that used in single drop temperature gradient columns (Reid 1976). Such an explosion mode is possible only under quite restrictive thermal conditions. As shown later in this report, such a mechanism is probably impossible for water and glass because film boiling would prevent liquid-liquid contact of a water drop surrounded by glass.

Johnson, Baker and Pavlik (1976) dropped comparatively large quantities $(1.4$ to $6.8 \mathrm{lb})$ of molten $\mathrm{UO}_{2}\left(3200^{\circ} \mathrm{C}\right)$ into a sodium pool maintained at $290^{\circ} \mathrm{C}$ and $630^{\circ} \mathrm{C}$. While some rapid boiling and pressure pulses in the liquid pool were caused by the contact of the hot material, there was no vapor explosion in any of the three tests. These results are in agreement with Fauske's (1973) view that a coherent vapor explosion between massive quantities of $\mathrm{UO}_{2}$ and sodium is probably impossible. However, from a purely phenomenological viewpoint, these tests are in consonance with Long's (1957) aluminum/water drop tests where he found that vapor explosions did not occur for shallow pools or 
for small quantities of molten metal. Since explosions did occur when larger quantities of aluminum were dropped into deeper pools, one can not be certain that larger-scale tests employing $\mathrm{UO}_{2}$ and sodium would not lead to explosions.

Vapor Explosions with Simulated Fluids

Extensive testing has been done with simulated fluids to gain a better understanding of vapor explosion mechanisms. A few typical studies will be described to typify the information gained.

Henry et al. (1974, 1976) at Argonne National Laboratory completed a series of tests using Freon/water and Freon/mineral oil systems. Contact configurations tested were:

- Freon dumped into hot liquid;

- hot liquid dumped into Freon;

- a sub-surface injection of water into freon 22;

- an above-surface injection of water into Freon 22.

The interaction vessel was a 10 -in. long segment of 4 -in.-dia stainless steel pipe.

Explosive interactions occurred under temperature conditions where the calculated interfacial temperature exceeded the spontaneous nucleation temperature of the Freon.

Typical results obtained by Henry et al. (1976) are shown in Figure 4. The dividing line between explosive and nonexplosive regions appears to be reasonably described by the interface temperature of $60^{\circ} \mathrm{C}$ which is the predicted homogeneous nucleation temperature of Freon (Henry et al. 1976). Another important finding was that the maximum explosive pressure measured was the saturation pressure of the working fluid corresponding to the homogeneous nucleation temperature.

When the interactions were carried out at ambient pressures of 2.2 bar and 8.0 bar, no explosive interactions occurred. This finding is shown graphically in Figure 5. The data shows the explosions can be entirely suppressed by imposing an ambient pressure above a certain value. Henry et al. (1976) suggest that this cessation of explosive events with increasing ambient pressure 


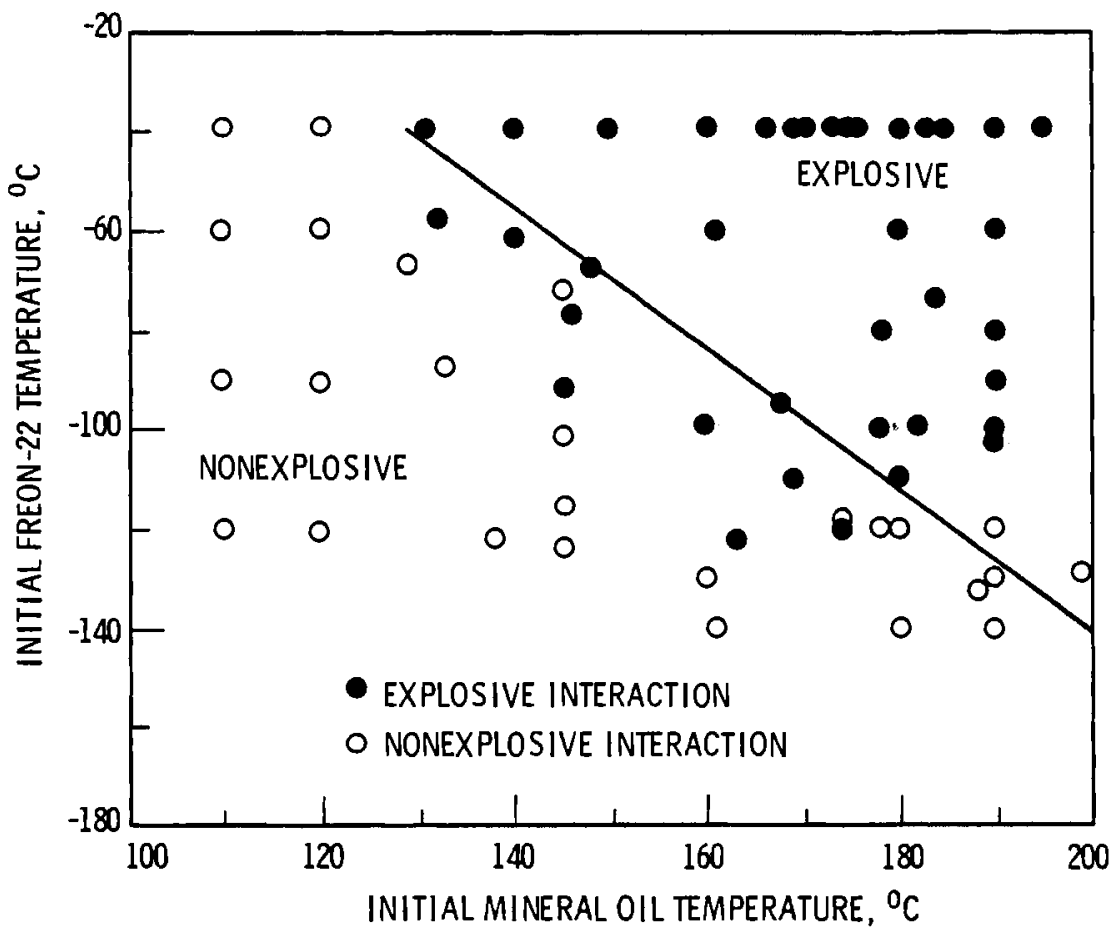

FIGURE 4. Freon-Mineral $0 i 1$ Interactions

(Henry et al. 1976)
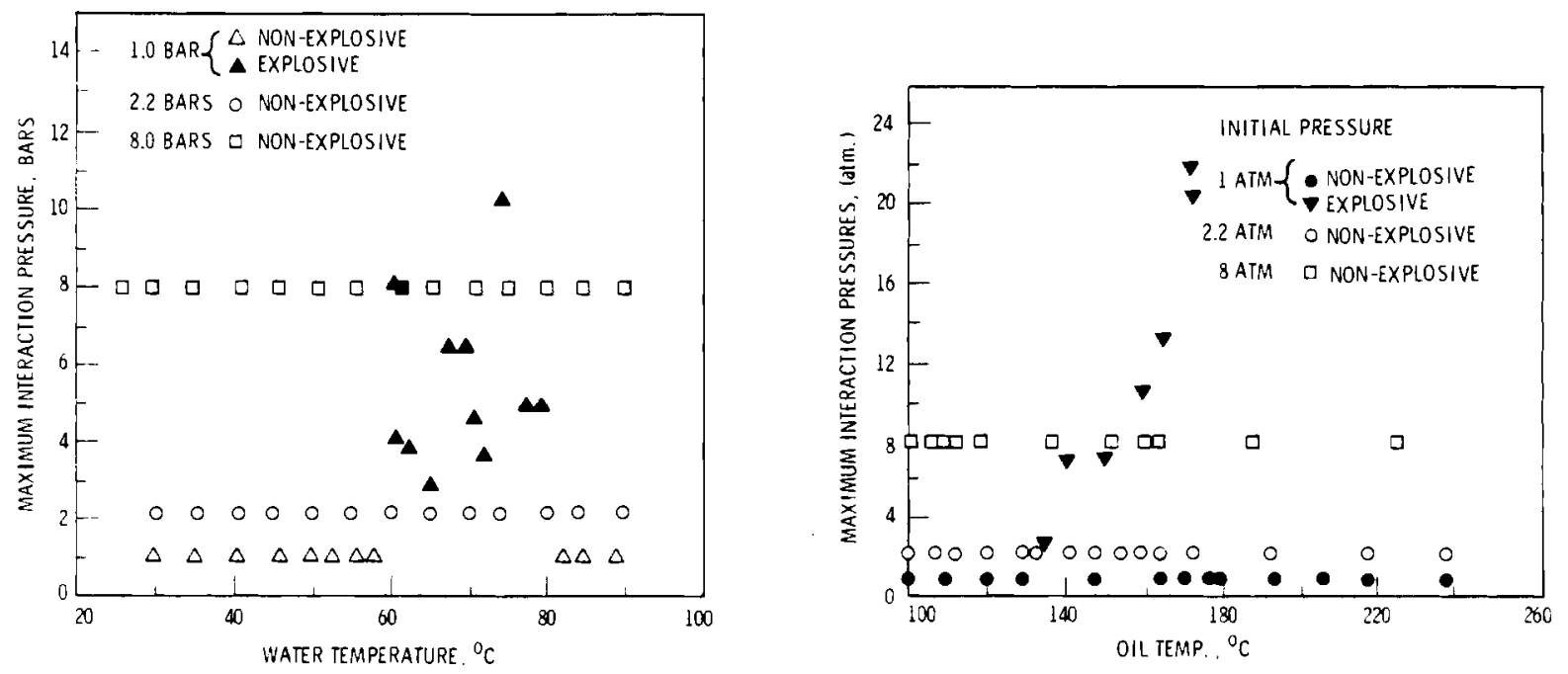

FIGURE 5. Effect of Ambient Pressure on Freon Vapor Explosions 
is closely related to the bubble growth characteristics (inertially versus thermally controlled growth) of the system. It is postulated that extensive inertially controlled growth will provide further fragmentation of liquid droplets and an incipient shock wave, whereas thermally controlled growth should provide little fragmentation and no incipient shock waves.

These experiments with simulated fluids appear to be consistent with results of water/metal interactions and with the explosion process diagram of Figure 1. Two observations which may have an impact on the evaluation of glass/water interactions are:

1. Explosive interactions can be suppressed by increasing the ambient pressure.

2. Freon can vapor-explode even when it is at its saturation temperature.

The second of these observations is unexpected on the basis of previous studies where it was invariably found that the exploding liquid had to be appreciably subcooled to trigger an explosion. This is a negative factor in the waste melter evaluation because it implies that vapor explosions cannot be prevented by keeping the aqueous feed at or near the boiling point. Additional work appears to be warranted to verify the possibility of vapor explosions with a cool fluid which is initially at its saturation temperature.

Water/Glass Interactions Under Natural and Forced Conditions

Arakeri, Catton and Kastenburg (1978) carried out an experimental study of water/glass interactions wherein $25-\mathrm{g}$ quantities of special glass (at $800^{\circ} \mathrm{C}$ ) were dropped into water at room temperature $\left(22^{\circ} \mathrm{C}\right)$. These experiments by UCLA researchers were a sequel to molten tin/water tests (Arakeri et al. 1975 ) and used glass to more closely simulate the thermal properties of molten nuclear fuel $\left(\mathrm{UO}_{2}\right)$. Under so-called "natural" conditions, the glass fell into a tank of water about $25 \mathrm{~cm}$ deep without external disturbances. "Forced" interactions were those in which an exploding wire (Chace and Moore 1959) imposed a pressure pulse on the falling globule of glass after it entered the water. 
The glass used in these experiments was made of $60 \% \mathrm{~B}_{2} \mathrm{O}_{3}$ and $40 \% \mathrm{PbO}$ (by weight) and was selected because it could be discharged rapidly from the melting crucible. The melt reportedly had a melting point of $750^{\circ} \mathrm{C}$ and, at a temperature of $900^{\circ} \mathrm{C}$ "the molten glass was almost as fluid as water at room temperature." Based on this qualitative description, the glass used was much less viscous than typical silica waste glasses.

Under natural conditions, the glass mass cooled and solidified in the water without appreciable fragmentation. The solidified mass was quite friable, as expected, but the cracks developed subsequent to solidification. For the "natural" fall conditions, no vapor explosions were observed.

When a shock wave was impressed on the falling globule by the exploding wire, weak vapor explosions were observed. The interactions which occurred appeared to follow the often observed vapor film collapse and buildup cycle indicated in Figure 1. This was apparent from high-speed photographs and pressure measurements obtained.

Particles of glass which resulted from the "forced" interaction were comparatively large in size, having a mass median diameter of approximately $2 \mathrm{~mm}$. This is a comparatively large particle size and, due to heat transfer limitations, the vapor explosions caused by molten glass under "forced" conditions were of low energy.

These tests with water and glass are consistent with expectations based on the model pictured in Figure 1 . Under natural fall conditions, a vapor film prevents water and highly fluid glass from contacting each other. By the time the glass cools to the Leidenfrost temperature, the viscosity has increased to the point where the collapsing vapor film is unable to cause fragmentation. If the vapor film is collapsed prematurely by a pressure pulse, liquid-liquid contact can occur, and resulting vapor film collapse and growth cycles can cause fragmentation. Surface area enhancement can improve heat transfer to the point where vapor is produced explosively.

Due to the higher viscosity of waste glasses, one can take the water/ glass results of Arakeri, Catton and Kastenburg (1978) as worst cases for waste glass. Therefore, water/glass interactions would be nonviolent except 
under unusual circumstances where a very low viscosity glass was involved or where energetic, vapor-collapsing triggers, like a shock wave, were impressed. Effect of Dissolved Gases on Vapor Explosions

Asher, Davies and Jones (1976) at Harwell in England dropped molten tin globules $\left(6 \mathrm{~g}\right.$ at $800^{\circ} \mathrm{C}$ ) into water of different temperatures containing varying amounts of dissolved gases $\left(\mathrm{O}_{2}, \mathrm{~N}_{2}, \mathrm{CO}_{2}\right.$ and $\left.\mathrm{N}_{2} \mathrm{O}\right)$. Both water temperature and the quantity of dissolved gases were found to play a critical role in determining whether a vapor explosion occurred.

With degassed water, explosions invaribly took place for water temperatures up to $53^{\circ} \mathrm{C}$. When the initial water temperature was higher than $53^{\circ} \mathrm{C}$, violent interactions ceased altogether, and the molten tin solidified without being fragmented. No change in behavior was observed when the water was saturated with nitrogen (solubility of $9 \mathrm{ml} \mathrm{kg}-1$ at $53^{\circ} \mathrm{C}$ ).

When the water was saturated with oxygen, the cut-off temperature was reduced from $53^{\circ} \mathrm{C}$ to $41^{\circ} \mathrm{C}$. The solubility of oxygen at $41^{\circ} \mathrm{C}$ is $23 \mathrm{ml} \mathrm{kg}^{-1}$, which is appreciably higher than that of nitrogen at $53^{\circ} \mathrm{C}$. Explosions could be completely suppressed by dissolved $\mathrm{CO}_{2}$ and $\mathrm{N}_{2} \mathrm{O}$. A certain concentration of dissolved gas ( $80 \mathrm{ml} \mathrm{kg} \mathrm{kg}^{-1}$ and $60 \mathrm{ml} \mathrm{kg}^{-1}$ for $\mathrm{CO}_{2}$ and $\mathrm{N}_{2} \mathrm{O}$, respectively) was required to totally suppress violent interaction at any water temperature. These concentrations are on $1 y$ about $10 \%$ of the saturated concentrations of these two gases at $20^{\circ} \mathrm{C}$ at 1 atm partial pressure.

The fact that dissolved gases can prevent violent interactions is consistent with the vapor explosion processes pictured in Figure 1. Mechanistically, one can visualize vapor film collapse cushioned by the presence of noncondensable gases. This would prevent fragmentation of the metal. The noncondensable gases would also provide gas nucleation sites and would reduce the degree of superheating which could be achieved. Both effects would act to prevent violent interactions.

The effect of dissolved gases is in marked contrast to the presence of gas bubbles. For example, Henry et al. (1976) found that explosive interactions between Freon-22 and water were only mildly influenced by the presence of gas bubbles in the water. This difference is explained when viewed on a 
local scale: The explosion is triggered when the vapor film, separating the hot and cool fluids, collapses. Whether or not fragmentation will occur depends on the cushioning effect of dissolved gases in the vapor bubble. The presence of a large gas bubble at some distance from the liquid-liquid interaction site would have little effect on the fragmentation process. Therefore, at least for small quantities of hot or cool fluids, the observed effect of noncondensable gases is understandable.

These observed effects of dissolved gases have potentially important implications for the liquid-fed melter, because a simple method for preventing vapor explosions, if such prevention were necessary, is suggested. The prevention method would involve the addition of $\mathrm{CO}_{2}$ or $\mathrm{N}_{2} \mathrm{O}$ to the motive air used to air-lift the aqueous waste into the melter. Carbon dioxide (or another soluble gas) would dissolve into the aqueous phase, and its presence would prevent explosive interactions, even if other conditions favored glass-feed steam explosions.

On the other hand, the observed phenomena indicate that air alone would not dissolve to an extent which would be great enough to totally suppress explosive interactions. Also, the existence of gas bubbles in either the glass or the aqueous feed cannot be cited as strong evidence against the possibility of vapor explosion. 
. 


\section{ASSESSMENT OF THE POTENTIAL OF A VAPOR EXPLOSION}

\section{IN A LIQUID-FED GLASS MELTER}

\section{GLASS SOLIDIFICATION PRIOR TO FILM-BOILING COLLAPSE}

One important constraint on violent glass/water interactions is the apparent requirement that transitional boiling begin prior to freezing of the hot glass. This requirement is consistent with the vapor explosion sequence pictured in Figure 1, where the collapse of a vapor film is required before fragmentation can take place. If the glass has solidified by the time the vapor film collapses, then fragmentation into sufficiently small particles is impossible and a vapor explosion is averted.

Three modes of boiling, depicted in Figure 6, are known to occur in the quenching of a hot solid in a liquid (Katz and Sliepcevich 1971). At high temperatures, film boiling is the mode of heat transfer, and a thin vapor film separates the two phases. After the hot material has cooled to point $B$, the so-called Leidenfrost point, the vapor film collapses, and a transition region is encountered.

This boiling mode is characterized by periodic superheating of liquid, flashing to vapor and vapor-film collapse. When the hot material is a solid, the boiling is unstable and noisy. With a hot liquid, the hydrodynamic violence can fragment the hot liquid and lead to a vapor explosion. Therefore, if the glass is sufficiently viscous at the Leidenfrost point, fragmentation will be minimal and a vapor explosion will not occur.

A theoretical model, based on Taylor instabilities caused by vapor film flow over a horizontal plate, was developed by Berenson (1961) to predict the temperature difference at the Leidenfrost point. Berenson's (1961) equation for the minimum temperature difference is

$$
\Delta T_{\text {min }}=0.127 \frac{\rho_{v f}^{\Delta h}}{k_{v f}}\left(\frac{\mu_{f}}{g\left(\rho_{\ell}-\rho_{v}\right)}\right)^{\frac{1}{3}}\left(\frac{g_{0} \sigma}{g\left(\rho_{\ell}-\rho_{v}\right)}\right)^{\frac{1}{2}}\left(\frac{g\left(\rho_{\ell}-\rho_{v}\right)}{\rho_{l}+\rho_{v}}\right)^{\frac{2}{3}},
$$




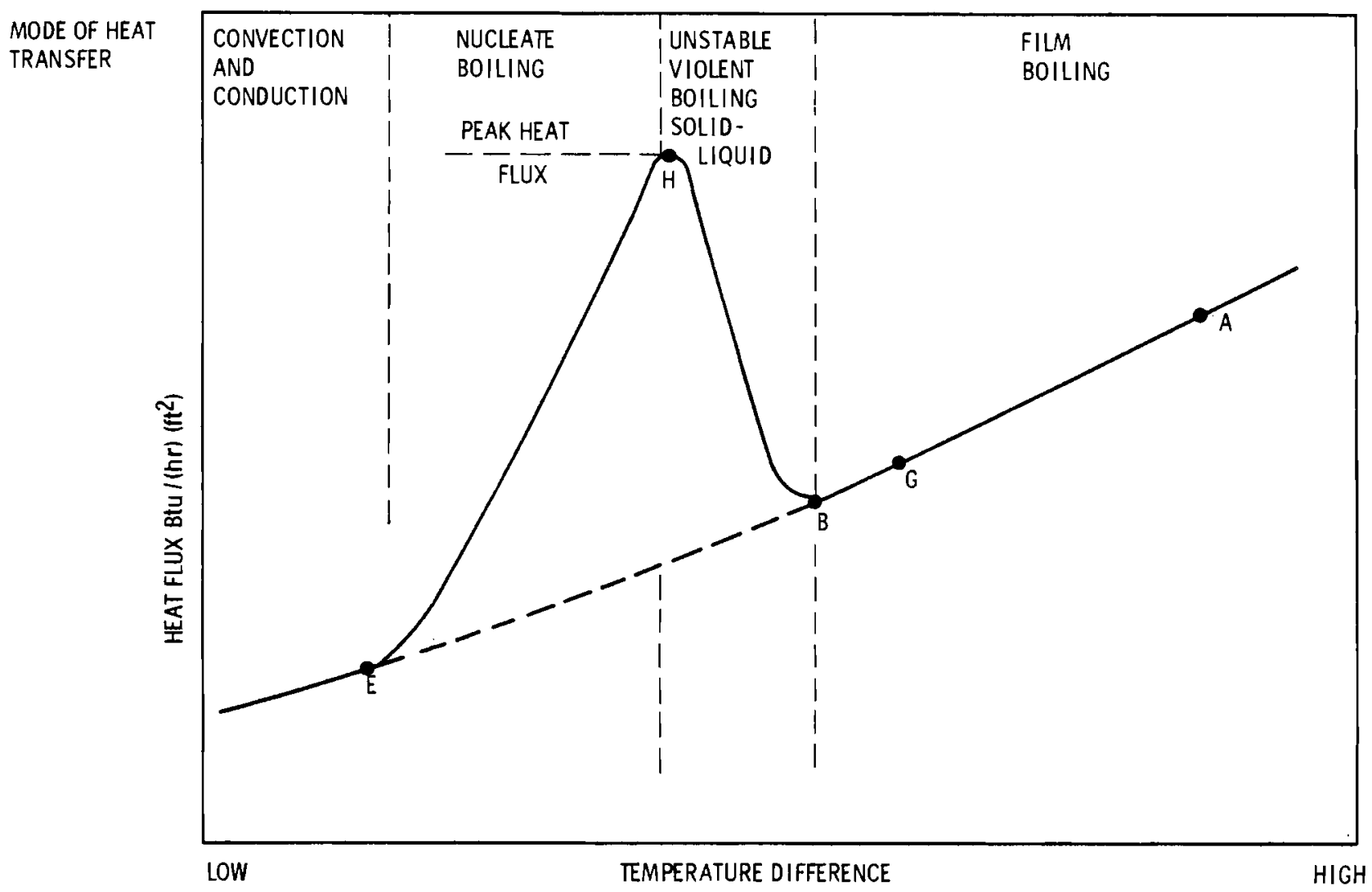

MECHANISMS OF BUBBLE FORMATION AT INTERFACE

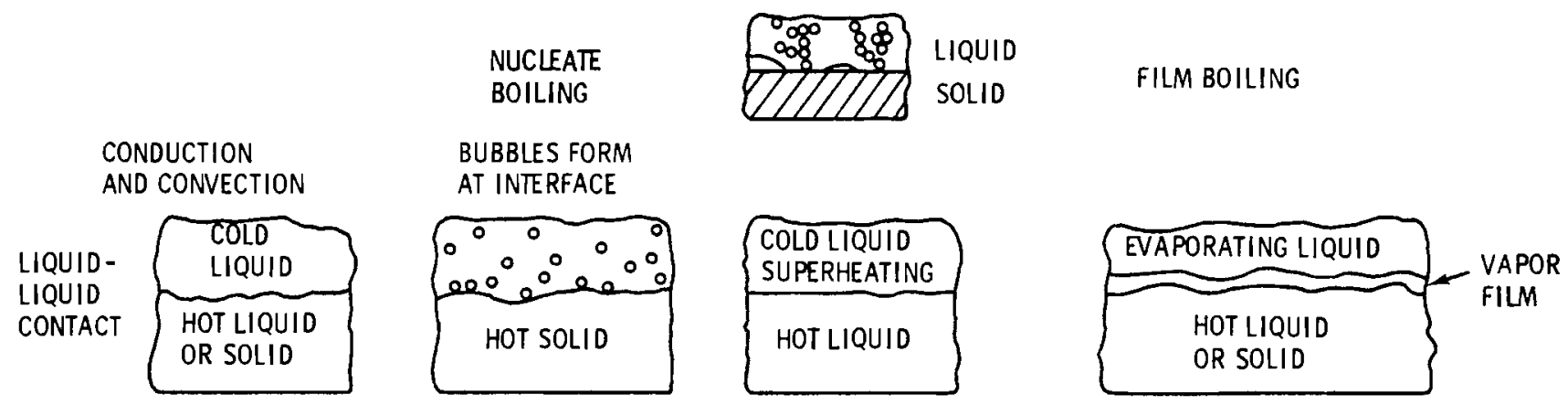

FIGURE 6. Boiling Heat Transfer Mechanisms 
where

$$
\begin{aligned}
\sigma= & \text { surface tension } \\
\Delta T_{\min }= & \text { minimum temperature difference required to maintain } \\
& f i l m \text { boiling, } \\
\rho_{v f}= & \text { density of vapor film, } \\
\Delta h= & \text { latent heat of vaporization of liquid, } \\
k_{v f}= & \text { thermal conductivity of vapor film, } \\
\mu_{f}= & \text { viscosity of vapor film, } \\
g= & \text { gravitational acceleration, } \\
\rho_{\ell}= & \text { density of liquid, } \\
\rho_{v}= & \text { density of vapor, } \\
g_{0}= & \text { gravitational conversion constant. }
\end{aligned}
$$

This equation was shown (Berenson 1961) to accurately predict the minimum temperature difference for film boiling of $n$-pentane and carbon tetrachloride at $1 \mathrm{~atm}$ pressure. However, for water and liquid metals, Equation (1) has been shown (Henry 1974) to greatly underpredict the minimum temperature difference. This discrepancy led Henry (1974) to modify Berenson's equation to account for transient wetting of the hot wall. Henry's correlation for the minimum temperature of $f i l m$ boiling is expressed as

$\frac{T_{\text {min }}^{1}-\left(T_{\text {min }}^{1}\right)_{I}}{\left(T_{\text {min }}^{1}\right)_{I}-T_{C}}=0.42\left\{\left(\frac{K_{c} \rho_{C} C_{C}}{K_{H} \rho_{H} C_{H}}\right)^{0.5} \cdot \frac{\Delta h}{C_{H}\left(\Delta T_{\text {min }}\right)_{I}}\right\}^{0.6}$,

where

$$
\begin{aligned}
T_{\text {min }}^{1}= & \text { minimum temperature to give film boiling } \\
\left(T_{\text {min }}^{1}\right)_{I}= & \text { minimum temperature for an isothermal surface, } \\
& \text { given in Equation }(1) \\
T_{C}= & \text { bulk temperature of cold liquid }
\end{aligned}
$$


$k_{c}, k_{H}=$ thermal conductivity of cold and hot materials

$\rho_{C}, \rho_{H}=$ density of cold and hot materials

$C_{C}, C_{H}=$ heat capacity of cold and hot materials

$\begin{aligned} &\left(\Delta T_{\min }\right)_{I}= \text { minimum temperature difference to give film boiling } \\ & \text { for an isothermal surface. }\end{aligned}$

$\left(T_{\min }^{1}\right)_{I}$ can be computed from the value of $\left(\Delta T_{\min }\right)_{I}$ given in Equation (1) using

$$
\left(T_{\min }^{1}\right)_{I}=T_{\text {sat }}+\left(\Delta T_{\min }\right)_{I}
$$

where

$$
T_{\text {sat }}=\text { saturation temperature at prevailing pressure. }
$$

Henry's correlation, Equation (2), accounts for subcooling in the boiling liquid and for temperature gradients in the hot material. It was shown by Henry (1974) to agree much better with film boiling data for water and liquid metals than Berenson's model, Equation (1).

More recently, Dhir and Purohit (1977) conducted experiments in which steel, copper and silver spheres of 19 and $25 \mathrm{~mm}$ dia were quenched in water at 0 to $45 \mathrm{~cm} / \mathrm{s}$ and $0^{\circ} \mathrm{C}$ to $50^{\circ} \mathrm{C}$ subcooling. They found the minimum filmboiling-temperature difference to be correlated by

$$
\Delta T_{\min }=101+8 \Delta T_{\text {sub }}
$$

where

$$
\Delta T_{\min }=\underset{\text { minimum temperature difference needed to support }}{\text { film boiling, }}
$$




$$
\Delta T_{\text {sub }}=\text { liquid subcooling, }{ }^{\circ} \mathrm{K} .
$$

In Equation (4), $\Delta T_{\min }$ can be expressed as

$$
\Delta T_{\min }=T_{\text {surface }}-T_{\text {sat }} \text {, }
$$

where

$$
\begin{aligned}
T_{\text {surface }}= & \text { surface temperature of sphere, } \\
T_{\text {sat }}= & \text { saturation temperature of water at prevailing } \\
& \text { pressure. }
\end{aligned}
$$

The degree of subcooling, $\Delta T_{\text {sub }}$ is defined as

$$
\Delta T_{\text {sub }}=T_{\text {sat }}-T_{\text {bulk }} \text {, }
$$

where

$$
T_{\text {bulk }}=\text { bulk temperature of water. }
$$

The experiments of Dhir and Purohit (1977) agreed only fairly with Henry's correlation, but agreed well with Equation (4).

Calculated, minimum surface temperatures, based on the Dhir and Purohit model are shown as a function of ambient pressure in Figure 7 . The minimum temperature rapidly decreases as water temperature increases. At 1 atm of pressure, and for a glass having a softening point of $600^{\circ} \mathrm{C}$, film boiling would prevent water and glass from contacting for water temperatures in excess of $50^{\circ} \mathrm{C}$.

For aluminum, with a melting point of $660^{\circ} \mathrm{C}$, this graph indicates that vapor explosions should be impossible for water temperatures above $42^{\circ} \mathrm{C}$, 


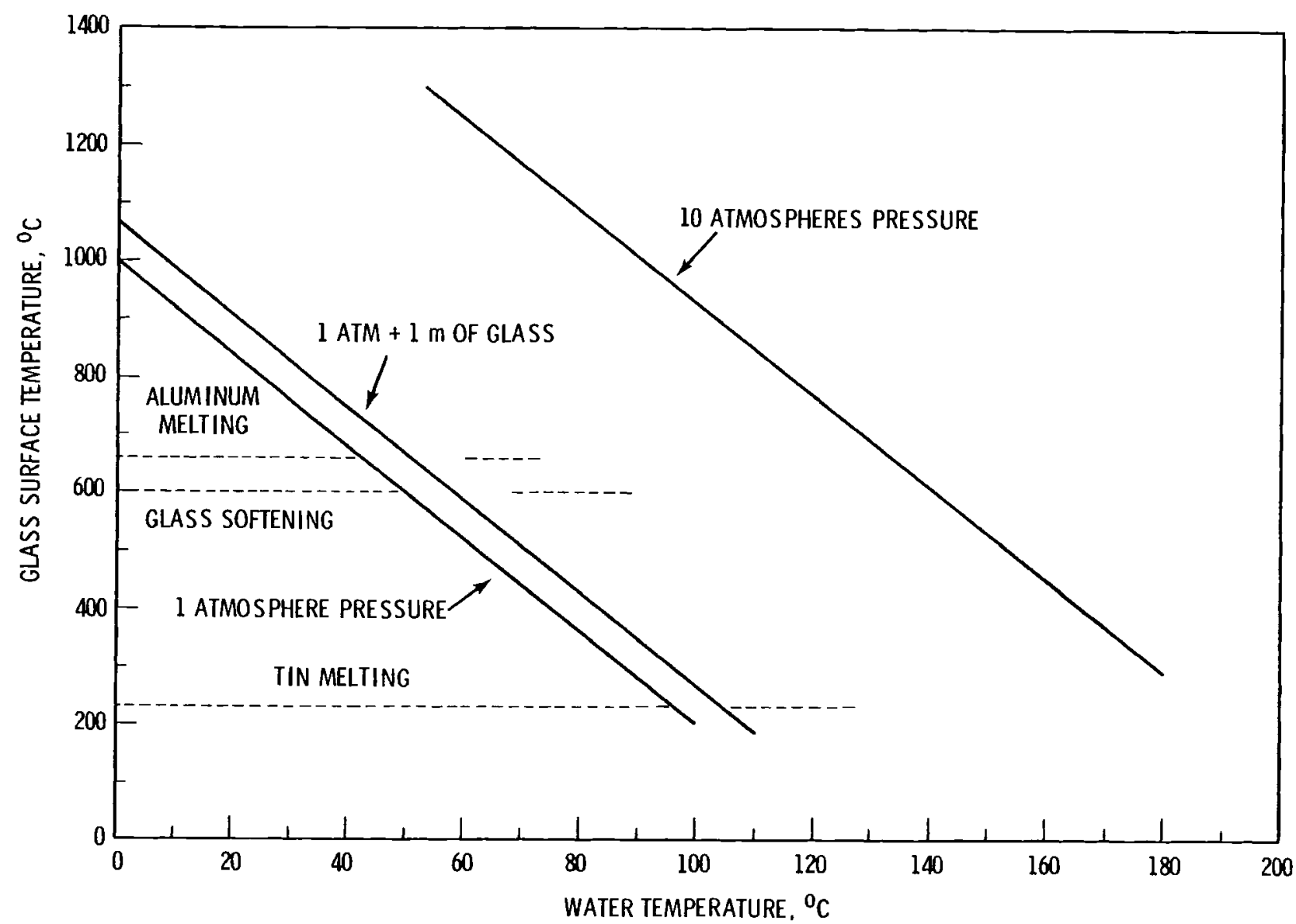

FIGURE 7. Minimum Glass Surface Temperature Required to Sustain FilmBoiling Based on Correlation of Dhir and Purohit (1977) 
which is supported by Long's results where the warmest water which would produce a vapor explosion was $50^{\circ} \mathrm{C}$. The pressure in the bottom of the aluminum/ water tests was slightly higher than $1 \mathrm{~atm}$, and this increased pressure may account for the slight underprediction of the film breakdown temperature.

For molten tin, the film-boiling collapse would not prevent vapor explosions unless the water temperature exceeded about $96^{\circ} \mathrm{C}$. However, as shown later, the interfacial temperatures obtained with tin below $300^{\circ} \mathrm{C}$ are lower than the spontaneous nucleation temperature of water.

Similar calculations carried out using Henry's (1974) correlation, Equation (2), are illustrated in Figure 8 . As indicated, film boiling is predicted to prevent direct contact between water and surfaces hotter than $650^{\circ} \mathrm{C}$. Thus, one would be led to conclude that aluminum/water interactions should be impossible at 1 atm pressure, and that water/glass interactions should be impossible for water temperatures above $20^{\circ} \mathrm{C}$. These limits are more restrictive than those predicted by the Dhir and Purohit (1977) correlation displayed in Figure 7 . These differences mainly reflected the differences in geometry for the two models ( $p l$ ane versus sphere for Figures 8 and 7 , respectively).

The film-boiling limit predicted by the Dhir and Purohit (1977) correlation appears to be the most applicable to water/glass interactions because of geometry considerations. The most important conclusion to be reached from film-boiling limits is that violent water/glass interactions should be impossible for water temperatures above $60^{\circ} \mathrm{C}$. Therefore, if the melter were operated with aqueous feed above $60^{\circ} \mathrm{C}$, violent water/giass interactions should be prevented by film-boiling considerations alone. Direct liquidliquid contact would be prevented by the vapor film, and the glass would be solid by the time the film collapsed.

\section{SPONTANEOUS NUCLEATION TEMPERATURE AT A LIQUID-LIQUID INTERFACE}

As discussed earlier in this report, upon sudden contact between hot and cool liquids, the interface temperature must exceed the spontaneous nucleation 


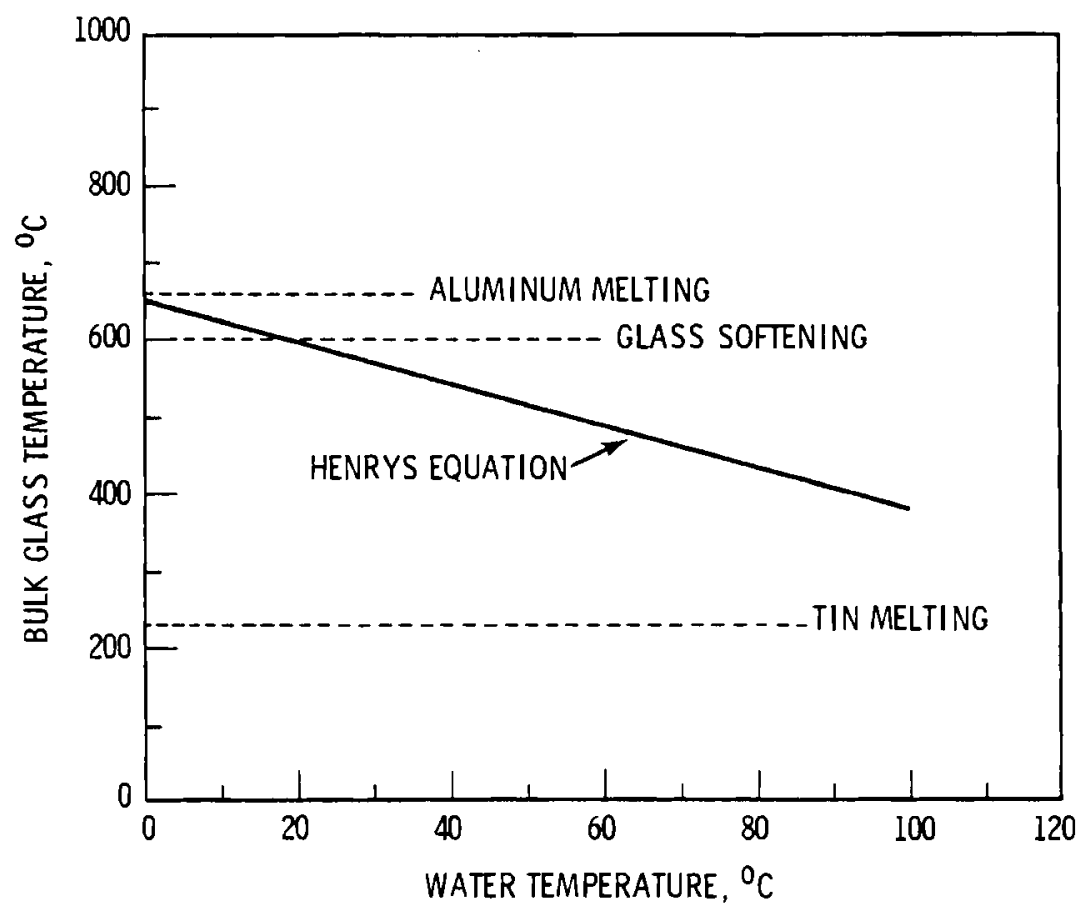

FIGURE 8. Minimum Glass Surface Temperature Required to Sustain FilmBoiling as Predicted in Henry's Correlation (Henry 1974) for $1 \mathrm{~atm}$ Pressure

temperature if a vapor explosion is to be triggered. When two substances are brought into sudden contact, mainly heat transfer occurs initially by conduction.

When two infinite slabs, initially at uniform temperatures $T_{H}$ and $T_{C}$, are suddenly brought into contact, the interface temperature may be computed by solving the transient heat conduction equation in both slabs. Assuming the temperature to be continuous at the interface, the temperature is computed to be (Carslaw and Jaeger 1959)

$$
\frac{T_{i}-T_{c}}{T_{H}-T_{C}}=\left(\frac{K_{H} \rho_{H} C_{H}}{K_{C} \rho_{C} C_{C}}\right)^{\frac{1}{2}} \text {, }
$$


where

$$
\begin{aligned}
& T_{i}=\text { temperature of interface } \\
& T_{H}=\text { bulk temperature of hot liquid } \\
& T_{C}=\text { bulk temperature of cold liquid } \\
& K=\text { thermal conductivity } \\
& \rho=\text { density } \\
& C=\text { heat capacity } \\
& C=\text { subscript referring to cold liquid } \\
& H=\text { subscript referring to hot liquid. }
\end{aligned}
$$

Equation (7) was numerically evaluated for glass and water and for aluminum and water and the results are shown in Figure 9 . For water at $100^{\circ} \mathrm{C}$ (typical of water interface in $f i l m$ boiling at one atm pressure) the data of Figure 7 indicates that the spontaneous nucleation temperature is exceeded for glass hotter than $360^{\circ} \mathrm{C}$. For the coolest water likely to be encountered, $20^{\circ} \mathrm{C}$, the spontaneous nucleation temperature is reached at a glass temperature of $430^{\circ} \mathrm{C}$. Both of these temperatures are below the softening point of waste glasses. Therefore, the spontaneous-nucleation temperature of water would be exceeded for any contact between water and molten glass.

From this calculation, we conclude that the spontaneous-nucleation criteria is met for water and molten glass, and the prevention of vapor explosions for the water/glass pair is due to other factors.

Also shown in Figure 9 is the interface temperature for the aluminum/water pair. The spontaneous-nucleation temperature of water is exceeded for all aluminum temperatures above the melting point. Thus, the spontaneous-nucleation criteria for aluminum and water is consistent with Long's (1957) tests which demonstrated that vapor explosions could be produced for aluminum temperatures above the melting point. 


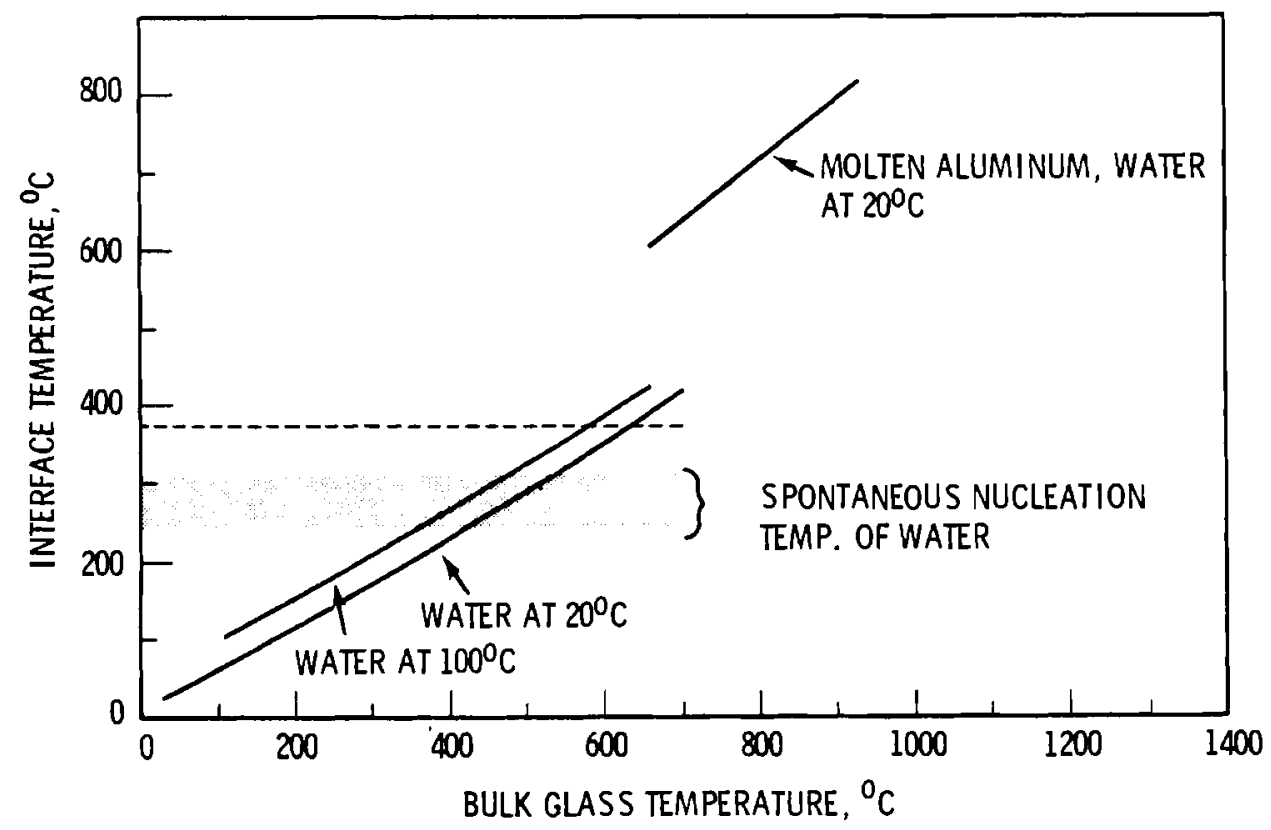

FIGURE 9. Interface Temperature Established upon Contact of Waste Glass and Aluminum with Water

\section{NUCLEATION BY SUSPENDED PARTICLES}

High-level waste feeds entering the melter would normally contain a high concentration of suspended particles, which could act as nucleation centers. If the particles nucleated a gas phase at a small degree of superheat, then superheat-type vapor explosions should be impossible. Two necessary conditions required for preventing superheating by suspended particles are the following:

- Particles cause nucleation at low superheats.

- Particle concentration is sufficiently high. Classical nucleation theory ( $B 1$ ander and Katz 1975) leads to the following expression for the homogeneous nucleation rate in a superheated liquid

$$
J=N\left(\frac{2 \sigma}{\pi m B}\right)^{\frac{1}{2}} \exp \left(\frac{-16 \pi \sigma^{3}}{3 k T\left(P_{V}-P_{L}\right)^{2}}\right)
$$


where

$$
\begin{aligned}
J & =\text { nucleation rate } \\
\sigma & =\text { surface tension } \\
m & =\text { mass of molecules in liquid } \\
B & =\text { a numerical factor, } \sim 2 / 3 \\
K & =\text { Boltzmann constant } \\
T & =\text { absolute temperature, } \\
P_{V} & =\text { vapor pressure in nucleated vapor bubble, } \\
P_{L} & =\text { ambient pressure in liquid. }
\end{aligned}
$$

As shown by Blander and Katz (1975), the pressure inside the critical bubble is different than the equilibrium vapor pressure, and the pressure difference may be estimated by:

$$
P_{V}-P_{L} \cong\left(P_{e}-P_{L}\right) \delta
$$

where now $P_{e}$ is the equilibrium vapor pressure.

The value of $\delta$ may be approximated as follows:

$$
\delta \cong 1-\frac{\rho_{\mathrm{g}}}{\rho}+1 / 2\left(\frac{\rho_{\mathrm{g}}}{\rho}\right)^{2}
$$

where

$$
\begin{aligned}
& \rho_{g}=\text { density of gas in bubbles, } \\
& \rho=\text { density of liquid. }
\end{aligned}
$$


If Equations (9) and (10) are used in Equation (8), the resulting expression, using common laboratory units, is:

$$
J \cong 3.73 \times 10^{35}\left(\frac{\rho^{2} \sigma}{M^{3} B}\right) \exp \left(\frac{-1.182 \times 10^{5} \sigma^{3}}{T\left(P_{e}-P_{L}\right)^{2} \delta^{2}}\right)
$$

where the units are $\mathrm{J}\left(\mathrm{cm}^{-3} \mathrm{~s}^{-1}\right), \rho\left(\mathrm{g} / \mathrm{cm}^{-3}\right), \sigma\left(\mathrm{erg} / \mathrm{cm}^{-3}\right), \mathrm{M}\left(\mathrm{g} \mathrm{mole} \mathrm{e}^{-1}\right), \mathrm{T}\left({ }^{\mathrm{O}_{\mathrm{K}}}\right)$, and $P_{L}(\mathrm{~atm})$.

When Equation (11) is evaluated as a function of temperature, it is found that the nucleation rate is negligibly small until the value of $T$ approaches 90\% of the critical temperature. At that temperature, the argument of the exponential factor decreases rapidly, and the overall nucleation rate increases by several orders of magnitude per degree Kelvin. For water, the nucleation rate becomes $10^{4}$ to $10^{6} \mathrm{~cm}^{-3} \mathrm{~s}^{-1}$ at a temperature of about $300^{\circ} \mathrm{C}$. Thus, the calculated spontaneous nucleation temperature is approximately $300^{\circ} \mathrm{C}$ for water.

The presence of a solid surface can lower the spontaneous nucleation temperature by reducing the work required to form a critical bubble. Instead of forming a spherical, critical bubble, the bubble forms a spherical cap on a solid surface as shown in Figure 10 .

For the heterogenous nucleation process shown schematically in Figure 10, classical nucleation theory leads to the following equation (B 1 ander and Katz 1975) for the nucleation rate per unit area

$$
J=N^{2 / 3} S\left(\frac{2}{\pi m B F}\right)^{\frac{1}{2}} \exp \left(\frac{-16 \pi \sigma^{3} F}{3 \kappa T\left(P_{v}-P_{L}\right)^{2}}\right) \text {, }
$$

where the terms are as defined in Equation (8) except $S \equiv(1+\cos \theta) / 2$ and $F \equiv\left(2+3 \cos \theta-\cos ^{3} \theta\right) / 4$ where $\theta$ is the contact angle between liquid, solid, and gas as shown in Figure 10. For water, taking surface area equal to $1 \mathrm{~cm}^{-2}$ per $\mathrm{cm}^{3}$ of liquid, Equation (12) can be written in terms of common laboratory units as: 


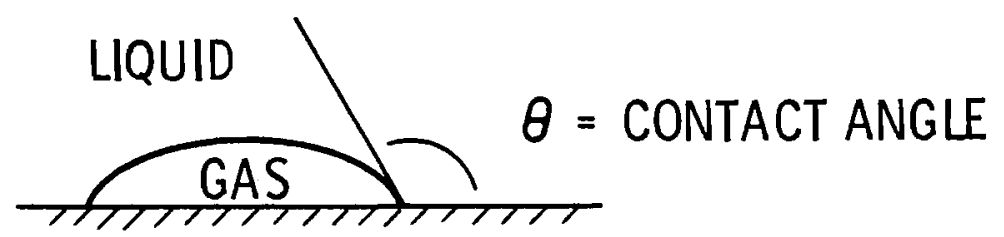

SOLID

FIGURE 10. Representation of a Nucleated Bubble on a Solid Surface

$$
\begin{aligned}
J & =1.85 \times 10^{26}\left(\frac{(1 \cos \theta)^{2}}{2+3 \cos \theta-\cos ^{3} \theta}\right)^{\frac{1}{2}}\left(\rho^{4 / 3} \sigma\right)^{\frac{1}{2}} \\
& \cdot \exp \left(\frac{-2.95 \times 10^{4} \sigma^{3}\left(2+3 \cos \theta-\cos ^{3} \theta\right.}{T\left(P_{e}-P_{L}\right)^{2} \delta^{2}}\right)
\end{aligned}
$$

The spontaneous nucleation temperature was evaluated as a function of using Equation (13), by setting $\mathrm{J}=10^{6} \mathrm{~cm}^{-3} \mathrm{~s}^{-1}$, and the result is shown graphically in Figure 11.

From Figure 11 it is evident that the spontaneous nucleation temperature is not reduced significantly until contact angles, larger than about $102^{\circ}$, are encountered. Only for contact angles near $180^{\circ}$ is the nucleating effect of solid surfaces dominant.

If suspended particles were nonsmooth on a miscroscopic scale and contained pockets of gas, nucleation per se would not be required. Rather, vapor would form on pre-existing pockets of gas at low degrees of superheat.

An estimate of the particle-number concentration, which would be required to prevent significant superheating, assuming that they possessed a contact angle of $180^{\circ}$, was made by calculating the spacing between particles arranged in a cubic array. Results are shown in Table 1. 


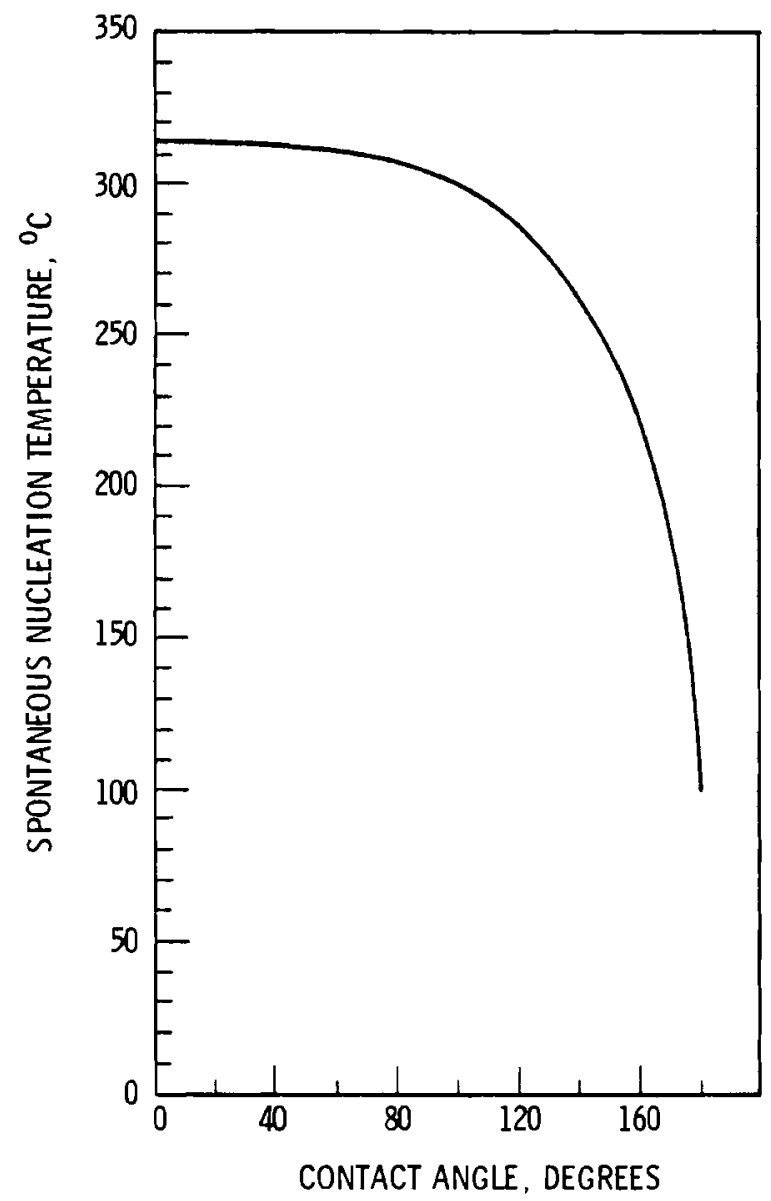

FIGURE 11. Effect of Contact Angle on Spontaneous Nucleation Temperature of Water at $1 \mathrm{~atm}$ Pressure

TABLE 1. Particle Spacing Versus Number Concentration for a Cubic Array

$\begin{array}{cll}\begin{array}{c}\text { Number } \\ \text { Per } \mathrm{cm}^{3}\end{array} & & \begin{array}{c}\text { Spacing, } \\ \mathrm{cm}\end{array} \\ 1 & & 1.0 \\ 8 & & 0.5 \\ 10^{3} & & 0.1 \\ 8 \times 10^{3} & 0.05 \\ 1 \times 10^{6} & 0.01\end{array}$

While we have no firm data, we judge that a spacing of at least $0.1 \mathrm{~cm}$ would be required to prevent superheating-type explosions. Based on this judgment, 1000 particles per $\mathrm{cm}^{3}$ would be required. This particle concentration 
is small compared to that calculated for waste feed containing $20 \%$ by weight of -200 mesh frit. The commonly used frit, premixed with feed, results in particle concentrations of more than $10^{6} / \mathrm{cm}^{3}$. Thus, for this feed material, the only question is the contact angle, or nucleating properties of the dispersed particles.

In summary, suspended particles will prevent superheating if they are both nonwetting and present in number concentrations larger than approximately $1000 / \mathrm{cm}^{3}$. For cases where a powdered frit is premixed with the aqueous feed, the number concentration is sufficiently high and superheating type explosions would be possible only if the contact angles were appreciably greater than $120^{\circ}$. Unfortunately, data on the nucleating properties of waste feed particles are not available; therefore, their presence cannot be counted on to prevent violent glass/water interactions.

\section{VISCOUS RETARDATION OF GLASS FRAGMENTATION}

One of the phenomena required for an energetic vapor explosion is atomi$z$ ation of the hot fluid. Such fragmentation is required to transfer sufficient heat to transfer from hot to cool fluids during the few milliseconds of time available.

For a sufficiently viscous hot fluid, atomization should be impossible within the time available, and thus one would expect the existence of a glass viscosity above which vapor explosions would be impossible. In this section, we examine the relationship between viscosity and drop shattering.

Several mechanisms are known to cause the breakup of fluid globules suspended in a second fluid. Well known splitting processes include:

- shear stresses

- impact pressure (Weber number type breakup)

- instability growth (Taylor instabilization)

While all of these processes could theoretically aid the breakup of glass in a ceramic melter, only the latter (Taylor instabilities) appears to be capable of causing breakup in the short times required for a coherent vapor explosion (Patel and Theofanous 1978). Therefore, the discussion which follows applies to globule breakup due to Taylor instability. 
If we consider a two-dimensional system of fluids of two densities as pictured in Figure 12, the interface between fluids is stable or unstable depending on whether the upper fluid is more or less dense than the lower fluid.

Taylor (1955) showed that if the more dense fluid is accelerated by the less dense fluid, a perturbation of the interface grows as $e^{n t}$, where $n$ is the growth rate constant and $t$ is time. For inviscid fluids, Taylor (1955) showed that $n$ was related to disturbance wave number, $k$, by

$$
n=\left(\frac{g\left(\rho_{2}-\rho_{1}\right) k}{\rho_{2}+\rho_{1}}\right)^{\frac{1}{2}}
$$

where

$$
\begin{aligned}
g= & \text { imposed acceleration } \\
\rho= & \text { fluid density } \\
K= & \text { wave number }=2 \pi / \lambda, \\
\lambda= & \text { wavelength of disturbance, } \\
1,2= & \text { subscripts referring to upper and lower fluids, } \\
& \text { respectively. }
\end{aligned}
$$

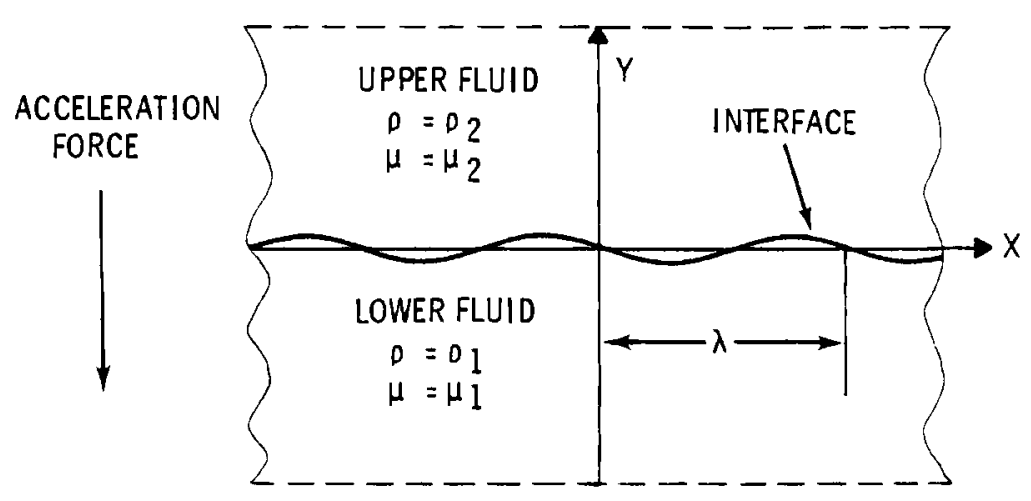

FIGURE 12. Motion at an Interface Between Two Fluids Experiencing Acceleration 
Equation (14) predicts the growth rate to increase as the wavelength of a disturbance decreases. For real fluids, viscosity and surface tension limit the growth rate of short wavelength disturbances. Bellman and Pennington (1954) analyzed the linearized equations of motion which accounted for both viscosity and surface tension. Numerical results presented by Bellman and Pennington for air and glycerine, for an imposed acceleration of $2 \times 10^{4} \mathrm{~cm} / \mathrm{s}^{2}$, are shown in Figure 13 .

As expected, surface tension and viscosity have little influence on long wavelength disturbances, but have a dominating effect on short wavelength disturbances. Perhaps the most significant phenomenon displayed in Figure 13 is the existence of a fairly sharp maximum in the growth rate versus wave number curve. The maximum indicates that interfacial breakup will be dominated by disturbances having the wavelength corresponding to the maximum $n$.

If surface tension is ignored, the dominant wavelength, $\lambda_{m}$, may be related to physical parameters by

$$
\lambda_{m}=\frac{4 \pi\left(\mu_{1}+\mu_{2}\right)^{2 / 3}}{g^{1 / 3}\left(\rho_{2}{ }^{2}-\rho_{1}{ }^{2}\right)^{1 / 3}} ;
$$

where

$$
\begin{aligned}
\lambda_{m} & =\text { wavelength of fastly growing disturbance } \\
\mu_{1}, \mu_{2} & =\text { viscosity of lighter and heavier fluids, respectively } \\
\rho_{1}, \rho_{2} & =\text { density of lighter and heavier fluids, respectively } \\
g & =\text { acceleration of interface. }
\end{aligned}
$$

Equation (15) was first presented by Bellman and Pennington (1954) and later by Hide (1955) who simplified a more exact treatment by Chandrasekhar (1955). 
The growth rate constant of this disturbance is given by Bellman and Pennington (1954) as

$$
n_{m}=\frac{g^{2 / 3\left(\rho_{2}-\rho_{1}\right) 2 / 3}}{2\left[\left(\mu_{1}+\mu_{2}\right)\left(\rho_{1}+\rho_{2}\right)\right]^{1 / 3}},
$$

and the interface disturbance initially grows as $e^{n_{m} t}$.

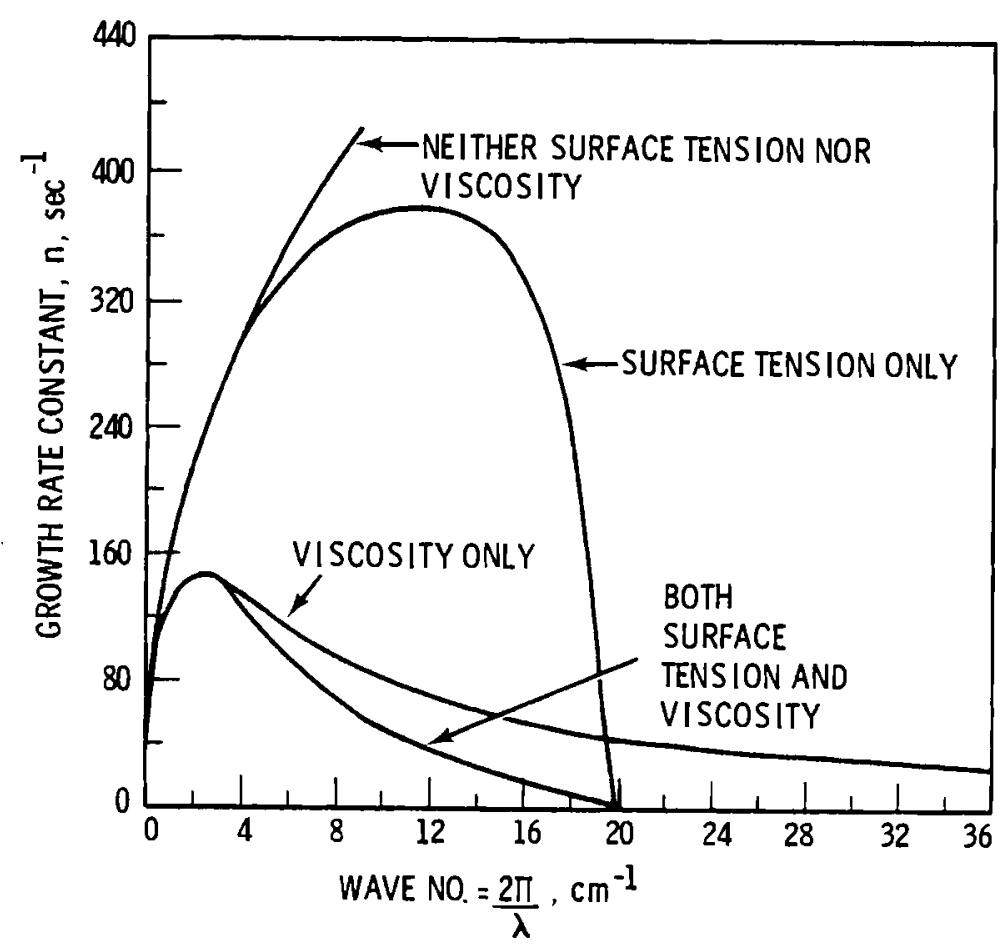

FIGURE 13. Effect of Viscosity and Surface Tension on Growth Rate of Interfacial Disturbance (Bellman and Pennington 1954)

Equation (15) was evaluated for glass and water using $\rho_{2}=3.0 \mathrm{~g} / \mathrm{cm}^{-3}$, $\rho_{1}=1.0 \mathrm{~g} / \mathrm{cm}^{-3}$, and neglecting $\mu_{1}$, compared to $\mu_{2}$ the glass viscosity. $\lambda_{m}$ was assigned a value of

$$
\frac{\lambda}{2}=0.14 \mathrm{~cm}
$$

based on Huggins' experiments as described by Witte et al. (1970). 
Huggins found that vapor explosions did not occur unless hot metal was dispersed into particles smaller than about $1400 \mu \mathrm{m}$. Using these numerical parameters, the viscosity for breakup into the required particles can be related to imposed acceleration by

$$
\mu=0.29 G^{1 / 2},
$$

where

$$
\begin{aligned}
& \mu=\text { viscosity in poise. } \\
& G=\text { acceleration in } G \text { 's whereas } G \text { corresponds to } 980 \mathrm{~cm} \mathrm{sec}^{-3} .
\end{aligned}
$$

Equation (17) is shown graphically in Figure 14.

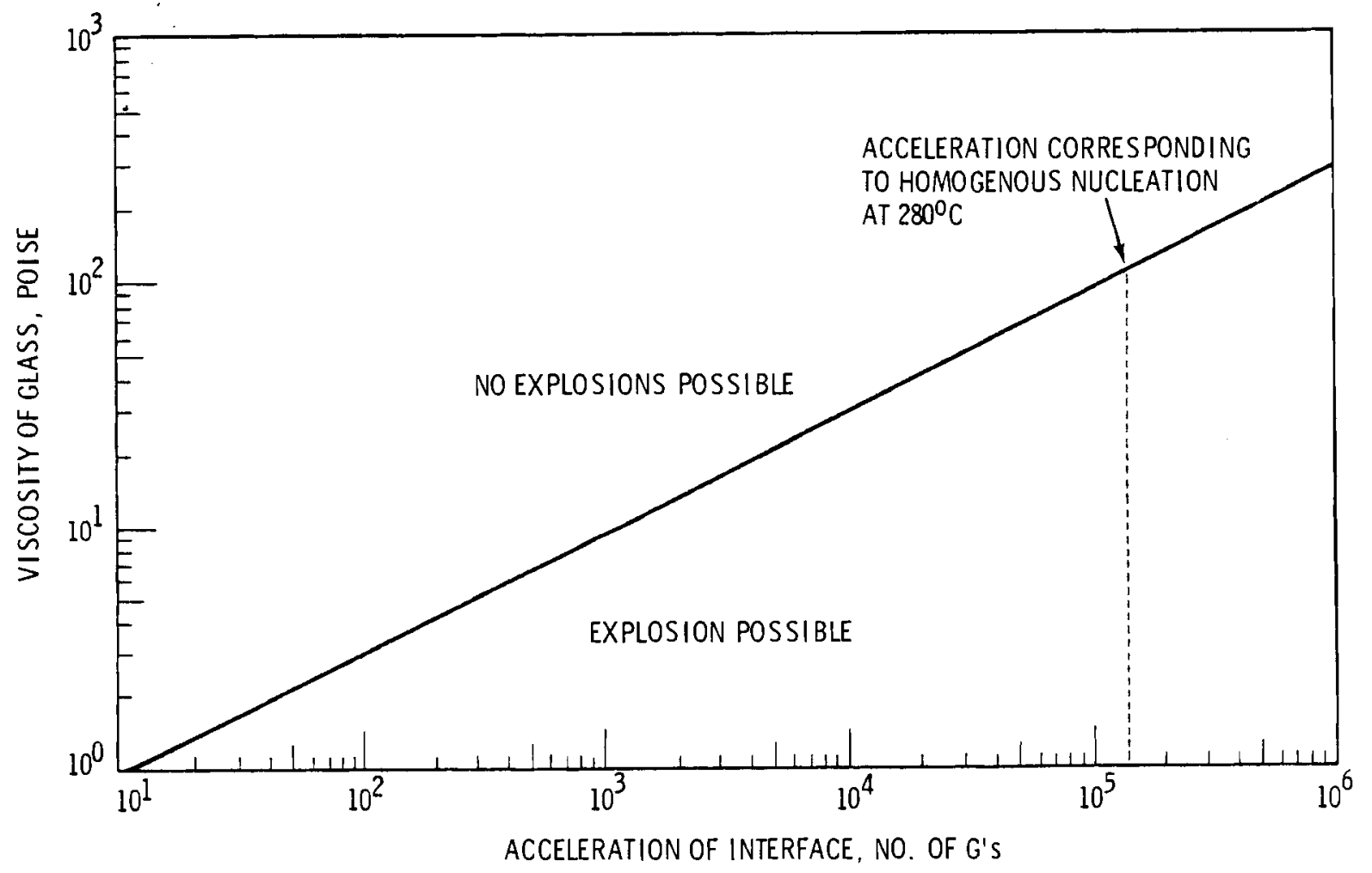

FIGURE 14. Effect of Viscosity on Acceleration Required to Disperse Water/Glass into $1400-\mu m$ Globules 
As indicated, viscosities above the line would prevent glass fragmentation of particles as small as $0.14 \mathrm{~cm}$; therefore, vapor explosions should be impossible.

An upper limit to acceleration which might be encountered in a glass melter was estimated by applying Newton's law of acceleration to a glass layer $0.14 \mathrm{~cm}$ thick under the influence of a pressure of $63 \mathrm{~atm}$, the vapor pressure of water at $280^{\circ} \mathrm{C}$. Based on this upper limit prediction, $G$ is estimated to be $1.5 \times 10^{5} \mathrm{G}$ 's and the corresponding viscosity is 100 poise.

At the moment of vapor-film collapse, glass should be nondispersible if its viscosity if higher than 100 poise. Referring to Figure 7 , vapor film collapses at a temperature which depends on the aqueous temperature and the ambient pressure. For water at $20^{\circ} \mathrm{C}$ and an ambient pressure of $1 \mathrm{~atm}, \mathrm{glass}$ temperature is predicted to be $840^{\circ} \mathrm{C}$ when film boiling collapses. At this temperature, typical waste glasses have viscosities of about 1000 poise; therefore, we conclude that viscous effects would prevent vapor explosions under ordinary conditions. However, if the glass had unusually low viscosity, or the aqueous waste was very c0ol, or a pressure pulse caused premature collapse of the vapor film, then glass viscosity at the moment of liquid-liquid contact could be too low to prevent fragmentation.

In summary, water/glass interactions have been shown to be nonviolent compared to metal/water interactions due to viscous retardation of the fragmentation process. Indeed, under normal melter operating conditions viscous effects alone are expected to prevent violent vapor explosions. Only under off-standard conditions where liquid-liquid contact occurs between water and a low-viscosity glass does it appear possible to have a violent water/glass interaction. 


\section{POTENTIAL FOLLOW-ON EXPERIMENTS}

Based on the work completed in this study, it was concluded that violent glass/water interactions are highly improbable under normal conditions in a liquid-fed glass melter. Thus, we would not expect to observe damaging vapor explosions in this melter. Unfortunately, however, the mechanisms which cause vapor explosions are not well enough understood to allow one to totally dismiss them. Therefore, experiments will be needed to confirm the predictions made herein. Important aspects of an experimental effort are briefly noted as follows.

\section{EXPERIMENTAL CONFIGURATION}

Following the example of Long (1957), it is suggested that dropping experiments be conducted in which molten glass is dropped into an aqueous phase. Such experiments would have to be carried out at a site which could accommodate an explosion and scattered molten glass.

\section{SIZE SCALE}

Large-scale experiments would be required because experience has shown that while small quantities of molten aluminum caused no explosions, larger quantities produced explosions under otherwise similar conditions. Based on the results of Long (1957) we recommend tests employing a few tens of kilograms of glass per test.

\section{VARIABLES TO BE EXPLORED}

The analyses presented in this study identified several factors which are expected to play a key role in preventing vapor explosions. Among those parameters which should be studied are the following:

- aqueous phase temperature

- glass temperature

- glass viscosity

- ambient pressure pulses 
- solids content of aqueous feed

- dissolved gas content of aqueous feed.

Some of these variables could probably be eliminated on the basis of positive experimental results or by design assessments. For example, if vapor explosions proved to be impossible with plain water, there would be no need to explore the effects of suspended solids or dissolved gases because both of these would diminish the probability of a vapor explosion.

A detailed experimental program will be developed to cover these parameters, including those which would apply to liquid-fed melter operation. 


\section{REFERENCES}

Arakeri, U. H., et al. 1975. An Experimental Study of the Thermal Interaction for Molten Tin Dropped into water. UCLA-ENG-7592, Univ. of California, Los Angeles, California.

Arakeri, U. H., I. Catton and W. E. Kastenburg. 1978. "An Experimental Study of the Molten Glass/Water Thermal Interaction Under Free and Forced Conditions." Nuclear Science Engineering 66:153-166.

Armstrong, D. R. 1972. Reactor Development Program Progress Report. ANL-RDP-2, Argonne National Laboratory, Argonne, I17inois.

Asher, R. C., D. Davies and P. G. Jones. 1976. Fuel-Coolant Interactions: Preliminary Experiments on the Effect of Gases Dissolved in the "Coolant." AERE-M-2861, Atomic Energy Research Establishment, Harwe11, England.

Bankoff, S. G., J. H. Jo and A. Ganguli. 1976. "Mechanisms of Vapor Explosions." Paper 18-2, International Conference on .Fast Reactor Safety, Chicago, Illinois.

Bellman, R., and R. H. Pennington. 1954. "Effects of Surface Tension and Viscosity on Taylor Instability." Quarterly of Applied Mathematics $12: 151-162$.

Berenson, P. J. 1961. "Film-Boiling Heat Transfer from a Horizontal Surface." American Society of Mechanical Engineering Transactions, Trans. ASME, Journal of Heat Transfer 83:351-358.

Bjorkquist, G. M. 1975. An Experimental Investigation of the Fragmentation of Molten Metals in Water. TID-26826, Massachusetts Institute of Technology, Cambridge, Massachusetts.

Blander, M., and J. L. Katz. 1975. "Bubble Nucleation in Liquids." AIChE Journal 21:833-848.

Board, S. J., and L. Caldarola. 1977. Fuel Coolant Interaction in Fast Reactors. Paper presented at ASME Symposium on the Thermal Hydraulic Aspects of Nuclear Reactor Safety in New York.

Board, S. J., C. L. Farmer and D. H. Poole. 1974. "Fragmentation in Thermal Explosions." International Journal of Heat Mass Transfer 17:331-339.

Board, S. J., R. W. Hall and R. S. Hall. 1975. "Detonation of Fuel Coolant Explosions." Nature 254:319-321.

Bocola, W., et al. 1972. "Survey of the Present State of Studies on the Solidification of Fission Product Solutions in Italy." Proceedings of Symposium on the Management of Radioactive Waste from Fuel Reprocessing, pp. 449-487, OECD, Paris, France. 
Bonniaud, R., et al. 1972. "Experience Acquise En France Dans Le Traitment Par Vitrification Des Solutions Concentrees De Produits De Fission." Proceedings of Symposium on the Management of Radioactive Wastes from Fuel Reprocessing, pp. 555-591, OECD, Paris, France.

Bradley, R. H. and L. C. Witte. 1972. "Explosive Interaction of Molten Metals Injected into Water." Nuclear Science Engineering 48:387-396.

Brauer, F. E., N. W. Green and R. B. Mesler. 1968. "Metal/Water Explosions." Nuclear Science Engineering 31:551-554.

Briggs, L. J. 1950. "Limiting Negative Pressure of Water." Journal of Applied Physics 21:721-722.

Buelt, J. L., et al. 1979. "A Review of Continuous Ceramic-Lined Melters and Associated Experience at PNL." Ceramics in Nuclear Waste Management, pp. 107-113. CONF-790420, Technical Information Center, United States Department of Energy, Springfield, Virginia.

Buchanan, D. J. 1974. "A Model for Fuel-Coolant Interactions." Journal of Physics D: Applied Physics 7:1441-1457.

Carbiener, W. A., et al. 1974. Physical Processes in Reactor Meltdown Accidents, Appendix VIII of Reactor Safety Study, Draft. WASH-1400, U.S. Atomic Energy Commission, Washington, D.C.

Carslaw, H. S., and J. C. Jaeger. 1959. Conduction of Heat in Solids, p. 88. Oxford University Press, London, England.

Chace, W. O., and H. K. Moore, eds. 1959. Exploding Wires, Vol. I, Plenum Press, New York, New York.

Chandrasekhar, S. 1955. "The Character of the Equilibrium of an Incompressible Heavy Viscous Fluid of Variable Density." Proceedings of the Cambridge Philosophical Society 51:162-178.

Colgate, S. A., and T. Sigurgeirsson. 1973. "Dynamic Mixing of Water and Lava." Nature 244:552-555.

Davis, Jr., W. 1967. Effect of Fission Product on the Production Capacity of the FINGAL Process. AERE-R-5268, United Kingdom Atomic Energy Agency, Harwe Tा, England.

Dhir, V. K., and G. P. Purohit. 1977. Subcooled Film-Boiling Heat Transfer from Spheres. ASME Paper No. 77-HT-78, Presented at the American Society of Mechanical Engineer's 17 th National Heat Transfer Conference, Salt Lake City, Utah. 
Drager, R. F., et a1. 1968. Development of the Phosphate Glass Process for Ultimate Disposal of High-Level Radioactive Wastes. BNL-50130 (T-505), Brookhaven National Laboratory, Upton, New York.

Drake, E., and R. C. Reid. 1977. "The Importation of Liquified Natural Gas." Scientific American 236:22-29.

"Eight Injured in Albany Plant Explosion." 1977. The Oregonian. Oct. 11, 1970 , p. A1, Portland, Oregon.

Fauske, H. K. 1973. "On the Mechanism of Uranium Dioxide - Sodium Interactions." Nuclear Science Engineering 51:95-101.

Fauske, H. K. 1974. "Some Aspects of Liquid-Liquid Heat Transfer and Explosive Boiling." Proceedings of Conference on Fast Reactor Safety, p. 992. CONF-740401-P1, U.S. Atomic Energy Commission, Los Angeles, California.

Flory, K., R. Paoli and R. Mesler. 1969. "Molten Metal-Water Explosions." Chemical Engineering Program 65:50-54.

Grover, J. R., et al. 1966. "The FINGAL Process." Proceedings of the Symposium on the Solidification and Long-Term Storage of Highly Radioactive Wastes. USAEC Report, CONF-660208, National Technical Information Service, Springfield, Virginia.

Henry, R. E. 1974. "A Correlation for the Minimum Film Boiling Temperature." In Heat Transfer - Research and Design AICHE Symposium Series, 70, ed., Dimitri Gidaspow, pp. 81-90. American Institute of Chemical Engineers, New York, New York.

Henry, R. E., et al. 1974. "Large-Scale Vapor Explosions." Proceedings of Conference on Fast Reactor Safety, p. 922. CONF-740401-P1, U.S. Atomic Energy Commission, Los Angeles, California.

Henry, R. H., et al. 1976. "Vapor Explosion Experiments with Simulant Fluids," International Conference on Fast Reactor Safety, pp. 1862. Chicago, Illinois.

Hess, P. D., and K. J. Brondyke. 1969. "Causes of Molten Aluminum-Water Explosions and Their Prevention." Metal Progress Apri1:93-100.

Hide, R. 1955. "The Character of the Equilibrium of an Incompressible Heavy Viscous Fluid of Variable Density: An Approximate Theory." Proceedings of the Cambridge Philiosophical Society 51:179-201.

Johnson, T. R., L. Baker and J. R. Pavlik. 1976. "Large-Scale Molten

Fuel-Sodium Interaction Experiments." Proceeding of the Fast Reactor Safety Meeting, p. 883-846. CONF-740401-P3, TIF, Springfield, Virginia.

Katz, D. L., and C. M. Sliepcevich. 1971. "LNG/Water Explosions: Cause and Effect." Hydrocarbon Processing Nov:240-244. 
Konstantinovich, A. A., et al. 1976. "Features of a Process for Vitrifying Radioactive Wastes Without Precalcination and Radionuclide Behavior in the Process." Paper SM-207/107, Presented at the IAEA International Symposium on Management of Radioactive Wastes from the Nuclear Fuel Cycle, Vienna, Austria.

Long, G. 1957. "Explosions of Molten Aluminum in Water: Cause and Prevention." Metal Progress. May:93-100.

McElroy, J.L., et al. 1970. Waste Solidification Program, Volume 5, Phosphate Glass Solidification Performance During the First Radioactive Tests in the Waste Solidification Engineering Prototypes. BNWL-1185, Pacific Northwest Laboratory, Richland, Washington.

McElroy, J. L., et al. 1971. Waste Solidification Program, Volume 7, Phosphate Glass Solidification Performance During Final Radioactive Tests in Waste Solidification Engineering Prototypes. BNWL-1541, Pacific Northwest Laboratory, Richland, Washington.

McElroy, J. L., et al. 1972. Waste Solidification Program, Volume 9, Pot Solidification Performance During Final Radioactive Tests in Waste Solidification Engineering Prototypes. BNWL-1628, Pacific Northwest Laboratory, Richland, Washington.

Nakanishi, E., and R. C. Reid. 1971. "Liquid Natural Gas-Water Reactions." Chemical Engineering Progress 67:36-41.

Nelson, W., and E. H. Kennedy. 1956a. "What Causes Kraft Dissolving Tank Explosions, I. Laboratory Experiments." Paper Trade Journal, July:50-56.

Nelson, W., and E. H. Kennedy. 1956b. "What Causes Kraft Dissolving Tank Explosions, II: Mill Investigations." Paper Trade Journal, July:30-32.

Patel, P. D., and T. G. Theofanous. 1978. Fragmentation Requirements for Detonating Vapor Explosions. PNE-78-122, Purdue University, West Lafayette, Indiana.

Plesset, M. S., and R. B. Chapman. 1971. "Collapse or an Initially Spherical Vapor Cavity in the Neighborhood of a Solid Boundary." Journal of Fluid Mechanics $47: 283$.

Reid, R. C. 1976. "Superheated Liquids." American Scientist 64:146-156.

Sallack, J. A. 1955. "An Investigation of Explosions in the Soda Smelt Dissolving Operation." Pulp and Paper Magazine (Canada) 56:114-118.

Skripov, V. P. 1974. Metastable Liquids. John Wiley and Sons, New York, New York. 
Taylor, G. I. 1955. "Instability of Liquid Surfaces When Accelerated in a Direction Perpendicular to Their Planes." Proceedings of the Royal Society (A) 201:192-196.

Williams, D. C. 1976. "A Critique of the Board-Hall Model." Paper 18-1, presented at International Conference on Fast Reactor Safety, Chicago, Illinois.

Wismer, K. L. 1922. "The Pressure-Volume Relation of Superheated Liquids." Journal of Physical Chemistry 26:301-315.

Witte, L. C., and J. E. Cox. 1978. "The Vapor Explosion - A Second Look" Journal of Metals Oct:29-35.

Witte, L. C., et al. 1970. "The Vapor Explosion." Journal of Metals $39: 39-44$.

Zyszkoswki, W. 1976. "Study of the Thermal Explosion Phenomenon in Molten Copper-Water System." International Journal on Heat Mass Transfer $19: 849-868$. 


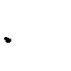




\section{DISTRIBUTION}

No. of

Copies

UNITED STATES

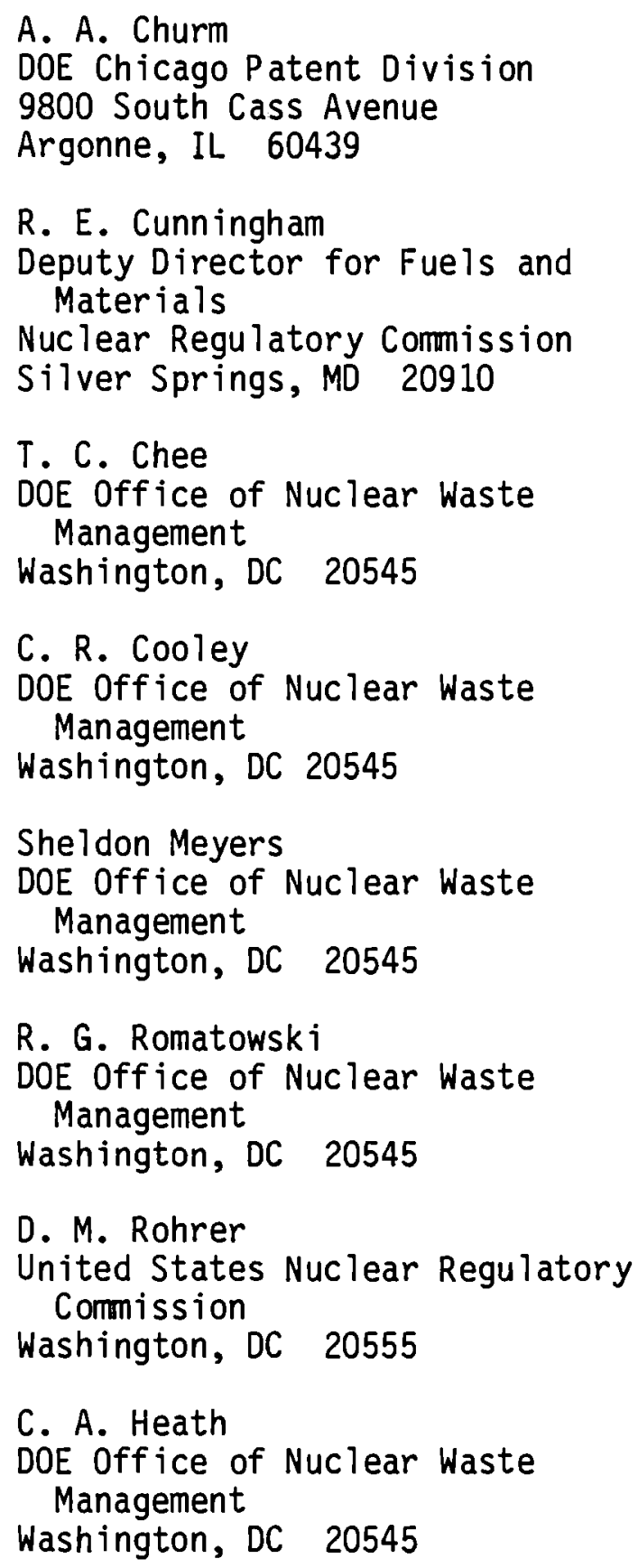

A. A. Churm

DOE Chicago Patent Division

9800 South Cass Avenue

Argonne, IL 60439
R. E. Cunningham
Deputy Director for Fuels and Materials
Nuclear Regulatory Commission
Silver Springs, MD 20910

T. C. Chee

DOE Office of Nuclear Waste

Management

Washington, DC 20545

C. R. Cooley

DOE Office of Nuclear Waste

Management

Washington, DC 20545

Sheldon Meyers

DOE Office of Nuclear Waste

Management

Washington, DC 20545

R. G. Romatowski

DOE Office of Nuclear Waste

Management

Washington, DC 20545

D. M. Rohrer

United States Nuclear Regulatory

Commission

Washington, DC 20555

C. A. Heath

DOE Office of Nuclear Waste

Management

Washington, DC 20545

No. of

Copies

G. Oertel

DOE Office of Nuclear Waste

Management

Washington, DC 20545

A. F. Perge

DOE Office of Nuclear Waste Management

Washington, DC 20545

R. D. Walton

DOE Office of Nuclear Waste

Management

Washington, DC 20545

W. E. Mott

DOE Division of Environmental

Control Technology

Washington, DC 20545

J. Neff, Program Manager

Department of Energy

Columbus Program Office

$505 \mathrm{King}$ Avenue

Columbus, $\mathrm{OH} 43201$

John Van Cleve

DOE Oak Ridge Operations Office

P.O. Box X

Oak Ridge, TN 37830

J. B. Whitsett

DOE Idaho Operations Office

550 2nd Street

Idaho Falls, ID 83401

E. S. Goldberg

DOE Savannah River Operations Office

P.0. Box A

Aiken, SC 29801 
No. of

Copies

27 DOE Technical Information Center

J. R. Berreth

Allied Chemical Corporation

550 2nd Street

Idaho Falls, ID 83401

Allied Chemical Corporation

(File Copy)

550 2nd Street

Idaho Falls, ID 83401

A. Williams

Allied-General Nuclear Service P.0. Box 847

Barnwel1, SC 29812

J. L. Jardine

Argonne National Laboratory

9700 South Cass Avenue

Argonne, IL 60439

M. M. Steindler/L. E. Trevorrow Argonne National Laboratory

9700 South Cass Avenue

Argonne, IL 60439

Wayne Carbiener

Battelle Memorial Institute

505 King Ave.

Columbus, $\mathrm{OH} 43201$

Beverly Rawles

Office of Nuclear Waste I solation

Battelle Memorial Institute

505 King Ave.

Columbus, $\mathrm{OH} 43201$

Brookhaven National Laboratory

Reference Section

Information Division

Upton, NY 11973
No. of

Copies

J. L. Crandal1

E. I. duPont DeNemours and Company

Savannah River Laboratory

Aiken, SC 29801

H. L. Hull

E. I. duPont DeNemours and Company

Savannah River Laboratory

Aiken, SC 29801

J. A. Kelley

E. I. duPont DeNemours and Company Savannah River Laboratory

Aiken, SC 29801

M. D. Boersma

E. I. duPont DeNemours and Company Savannah River Laboratory

Aiken, SC 29801

George Wicks

E. I. duPont DeNemours and Company Savannah River Laboratory

Aiken, SC 29801

Tom Willis

E. I. duPont DeNemours and Company Savannah River Laboratory

Aiken, SC 29801

H. Henning

Electric Power Research Institute 3412 Hillview Avenue

P.0. Box 10412

Palo Alto, CA 94301

Environmental Protection Agency

Technology Assessment Division

(AW-559)

Office of Radiation Programs

Washington, DC 20460 
No. of

Copies

R. G. Barnes

General Electric Company

175 Curtner Avenue (M/C 858)

San Jose, CA 95125

Los Alamos Scientific Laboratory (DOE)

P.0. BOX 1663

Los Alamos, NM 87544

J. P. Duckworth

Plant Manager

Nuclear Fuel Services, Inc. P.0. Box 124

West Valley, NY 14171

J. G. Cline, General Manager

NYS ERDA

Agency Building \#2

Empire State Plaza

Albany, NY 12233

Oak Ridge National Laboratory (DOE)

Central Research Library

Document Reference Section

P.0. Box X

Oak Ridge, TN 37830

E. H. Kobisk

Solid State Division

Oak Ridge National Laboratory

Oak Ridge, TN 37830

R. Roy

Pennsylvania State University

Materials Research Laboratory

University Park, PA 16802

J. Braithwaite

ORG 5831

Sandia Laboratories

P.0. Box 5800

Albuquerque, NM 87185
No. of

Copies

W. Weart

Sandia Laboratories

Albuquerque, NM 87107

D. E. Ferguson

Union Carbide Corporation (ORNL)

Chemical Technology Division

P.0. Box $Y$

Oak Ridge, TN 37830

H. W. Godbee

Union Carbide Corporation (ORNL)

Chemical Technology Division

P.0. Box $Y$

Oak Ridge, TN 37830

FOREIGN

D. W. Clelland

United Kingdom Atomic Energy Authority

Risley, ENGLAND

E. R. Merz

Institut fur Chemische

Technologie

Kernforschungsanloge Julich

GmbH

D517 Julich

Postfach 365

Federal Republic

WEST GERMANY

R. Bonniaud

Center de Marcoule

B.P. 170

30200 Baguols-Sur-Ceze

FRANCE 
No. of

Copies

C. Sombret

Centre de Marcoule

B.P. 170

30200 Baguols-Sur-Ceze

FRANCE

F. Laude

Centre de Marcoule

B.P. 170

30200 Baguols-Sur-Ceze

FRANCE

H. Krause

Kernforschungszentrum Kar lsruhe GmbH (KfK)

Postfach 3640

D7500 Karlsruhe

WEST GERMANY

S. Tashiro

Japan Atomic Energy Research Institute

Environmental Safety Research Laboratory

1-1-13, Shibashi

Minatopku, Tokyo

JAPAN

2 International Atomic Energy Agency

Kartner Ring 11

P.0. Box 590

A-1011, Vienna, AUSTRIA

B. Morr is

Atomic Energy Research

Establishment,

Harwe 11, Didcot,

Berks, ENGLAND

\section{ONSITE}

3 DOE Richland Operations Office

P. A. Craig

H. E. Ransom

M. J. Zamorsk $i$
No. of

Copies

6 Rockwe 11 Hanford Operations

L. Brown

B. A. Higley

M. J. Kupfer

G. Reep

D. D. Wodrich

File copy

Exxon Nuclear Company

S. J. Beard

Westinghouse Hanford Company

A. G. Blasewitz

48

Pac if ic Northwest Laboratory

S. M. Barnes

W. J. Bjorklund

H. T. Blair

W. F. Bonner

R. A. Brouns

J. L. Buelt (10)

L. A. Chick

R. D. Dierks

M. S. Hanson

A. J. Haverfield

M. H. Henry

L. K. Holton

J. H. Jarrett

D. E. Knowlton

C. A. Knox

D. E. Larson

S. A. McCullough

J. L. MCE lroy

G. B. Mellinger

J. E. Mendel

F. A. Miller

R. E. Nightingale

K. H. Oma

A. M. Platt

D. L. Prezbindowski (2)

W. A. Ross

J. M. Rusin 
No. of

Copies

D. H. Siemens

S. C. Slate

C. L. Timmerman

R. T. Treat

Technical Information (5)

Publishing Coordination $\mathrm{YO}(2)$

Distr -5 
